University of San Diego

Digital USD

2012-05-01

\title{
Preparing Global Leaders: A Theoretical Model for Understanding the Development of Intercultural Competency
}

Cynthia Ann Martinez PhD

University of San Diego

Follow this and additional works at: https://digital.sandiego.edu/dissertations

Part of the Leadership Studies Commons

\section{Digital USD Citation}

Martinez, Cynthia Ann PhD, "Preparing Global Leaders: A Theoretical Model for Understanding the Development of Intercultural Competency" (2012). Dissertations. 834.

https://digital.sandiego.edu/dissertations/834

This Dissertation: Open Access is brought to you for free and open access by the Theses and Dissertations at Digital USD. It has been accepted for inclusion in Dissertations by an authorized administrator of Digital USD. For more information, please contact digital@sandiego.edu. 


\title{
PREPARING GLOBAL LEADERS: \\ A THEORETICAL MODEL FOR UNDERSTANDING THE DEVELOPMENT OF INTERCULTURAL COMPETENCY
}

\author{
by \\ CYNTHIA ANN MARTINEZ \\ A dissertation submitted in partial fulfillment \\ of the requirements for the degree of \\ Doctor of Philosophy \\ University of San Diego
}

May 2012

Dissertation Committee

Lea Hubbard, Ph.D.

Noriyuki Inoue, Ph.D.

Erika Nash, Ph.D. 
() Copyright by Cynthia Ann Martinez

All Rights Reserved 


\begin{abstract}
As globalization increases, organizations are seeking individuals that have developed intercultural competency (ICC) and are prepared to lead for the $21^{\text {st }}$ century. Although there are competing definitions among scholars as to what characteristics (ability, attitude, awareness, behaviors, knowledge, skills, or values) make up ICC (Ang \& Van Dyne, 2008; Bennett \& Bennett, 2004), a considerable body of research has found that studying abroad is one of the best ways for undergraduate students to develop at least one characteristic of ICC (Chieffo \& Griffths, 2004; Deardorff, 2006; Sheridan, 2005). The question remains, however, whether or not study abroad programs can contribute to ICC development among graduate students, particularly those who are enrolled in a leadership studies program claiming to prepare global leaders.

The purpose of this study was to investigate the experiences of 14 graduate students who participated in a short-term study abroad program at two different universities and to assess ICC development. The two universities that were selected are the only doctoral leadership programs in the United States of America to require an international experience. Using a comparative case study methodology, this study answered the following research questions: How do graduate students at two different institutions who are enrolled in a leadership studies program define their ICC as a result of a short-term study abroad course experience? What factors facilitated or constrained students to develop the seven characteristics of ICC? How do we account for the similarities and differences experienced by the participants both within and across the two university programs along the seven characteristics of ICC?
\end{abstract}

Findings from the study validated the use of all seven characteristics of ICC, but importantly, also revealed additional key factors that were identified by graduate students 
as contributing significantly to their ICC. As a result of this study, a multi-layered theoretical model for understanding the development of ICC was created to assist international educators who are developing, planning, and assessing study abroad programs for graduate students. This new theoretical model will also help students understand their own ICC development and the characteristics needed to become more interculturally competent. 


\section{Dedication}

I dedicate this doctoral dissertation to my husband Gene and two children, Carissa and Gabriel. Thank you for your continuous support, encouragement, and sacrifices during my journey. 


\section{Acknowledgments}

There are several individuals and groups of people who have guided and supported me through my doctoral studies and dissertation process. First, I would like to acknowledge the faculty and staff at the University of San Diego (USD). I would like to thank my chair, Dr. Lea Hubbard for her expertise, precise and timely comments, and unwavering support throughout this journey. You have had a profound impact on my academic growth and development. Thank you to my committee members, Dr. Noriyuki Inoue and Dr. Erika Nash for offering valuable insight and guidance.

My doctoral studies would not have been possible if it was not for the financial support provided to me from the University of San Diego School of Leadership and Education Sciences. Thank you to Dean Paula Cordeiro, Assistant Dean Linda Dews, and the Department of Leadership Studies for providing funding through the Dean's Merit Scholarship, the Diversity Scholarship, and the Exceptional Funding Request.

Second, I would like acknowledge the faculty and staff at the University of Southern California (USC) Annenberg School for Communication and Journalism. Thank you to the senior administration team for supporting my professional, academic, and personal development over the years. I am grateful to work with an amazing group of colleagues that are supportive and encouraging. I would also like to thank the Undergraduate Advisement \& Academic Services team for their support and understanding throughout this process and the faculty who would stop me in the halls to give me words of encouragement. Thank you.

Third, my sincere and deepest appreciation is expressed to the 14 graduate students who graciously agreed to participate in this study. Their thoughtful and 
insightful comments and stories about intercultural competency form the basis of this research. I hope we will have opportunities to continue to work together. In addition, I am very appreciative of the two institutions for their cooperation in the data collection process.

Finally, I would like to thank my husband Gene Martinez, children Carissa and Gabriel, friends, and family for being so understanding and encouraging during my demanding schedule with work and school. Your support has meant a great deal to me. 
Approval Page ......................................................................................................... ii

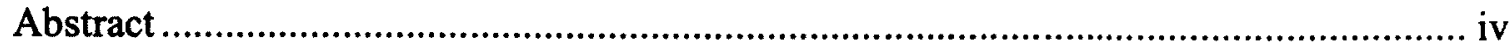

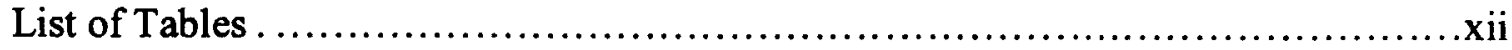

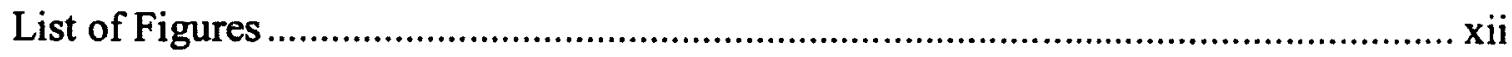

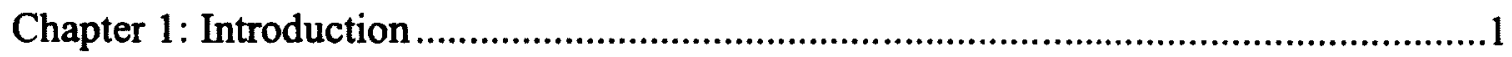

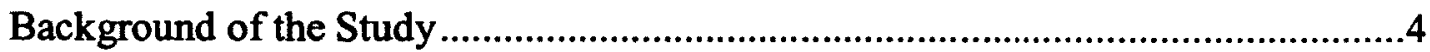

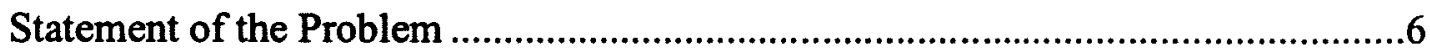

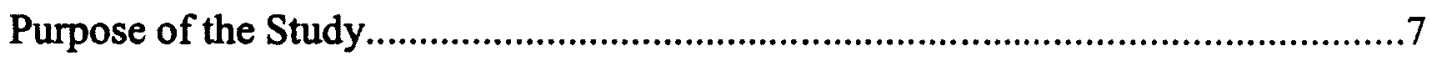

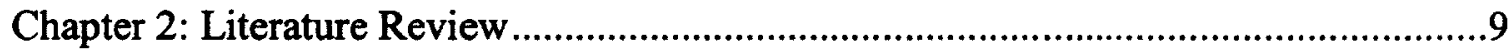

Terms Associated with Measuring Intercultural Competency .................................10

What is Intercultural Competency? ......................................................................11

Intercultural Competency Models .....................................................................12

Characteristics of Intercultural Competent Individual .............................................14

How do we Develop Intercultural Competency? ..................................................17

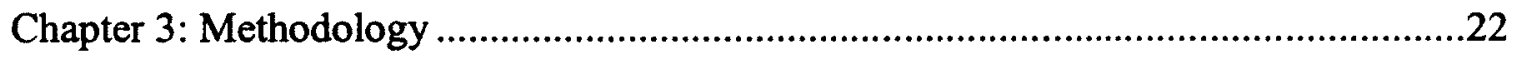

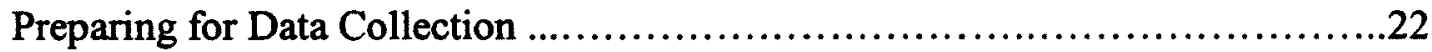

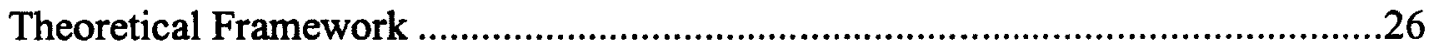

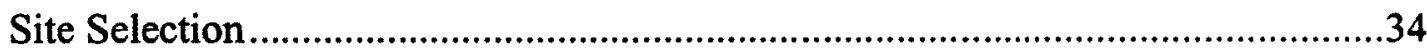

Unique Purposeful Sampling .......................................................................35

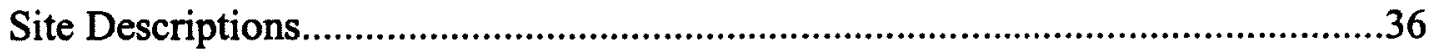

Profile of Private Catholic University............................................................36

Profile of Private Baptist University...............................................................40

Data Collection Procedures ..................................................................................41

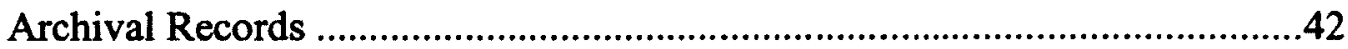

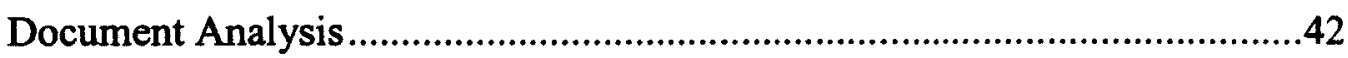

Semi-Structured Interviews ...............................................................................43

Interview Procedures .........................................................................................44

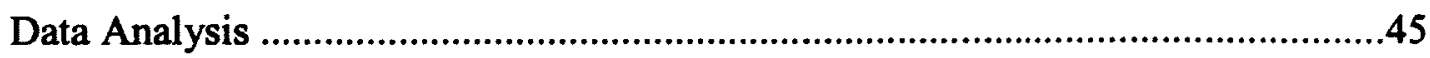

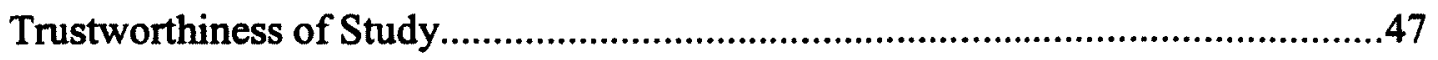


Limitations.

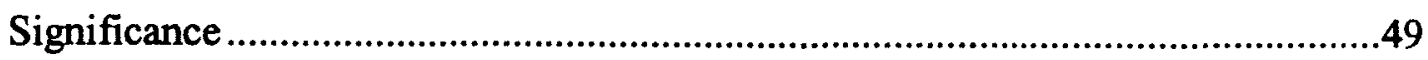

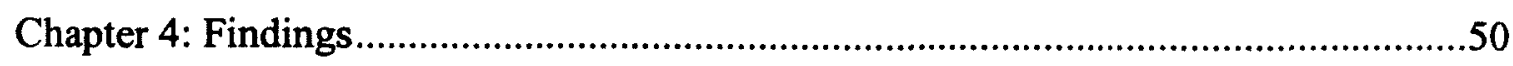

How Participants Confirmed the Seven Characteristics of ICC..............................51

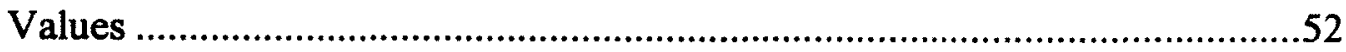

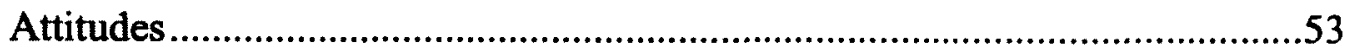

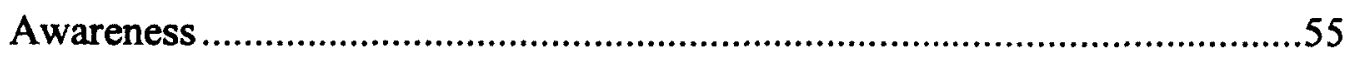

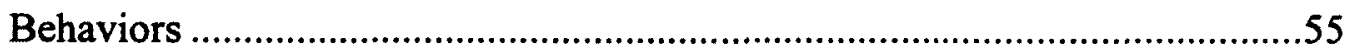

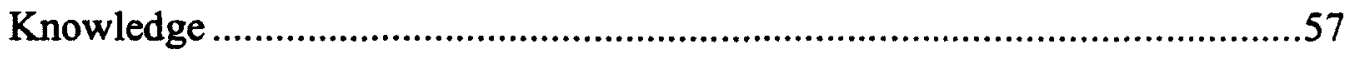

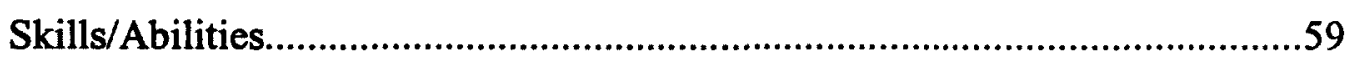

Transformative Learning: Interconnecting the Seven Characteristics of ICC ........60

Additional Factors Contributing to Existing Model.................................................65

Prior Experiences Shaped Intentions to Develop ICC.....................................65

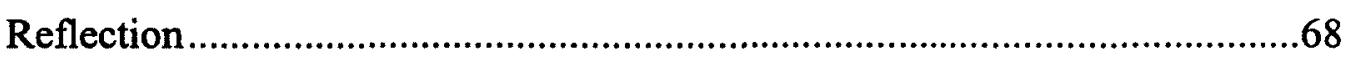

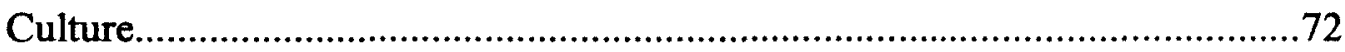

Cognitive Dissonance ..................................................................................

Revised Theoretical Model for Developing ICC …………...............................

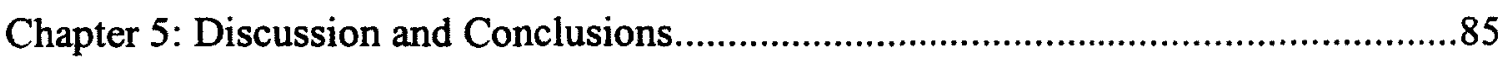

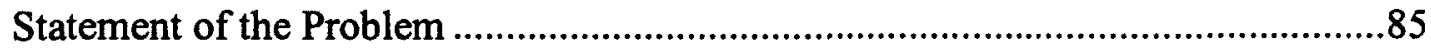

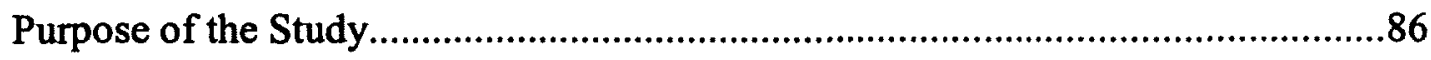

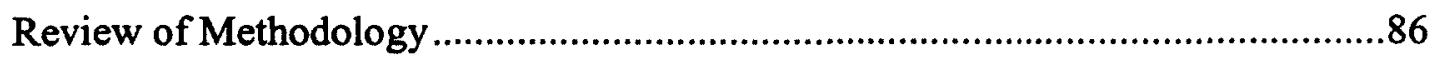

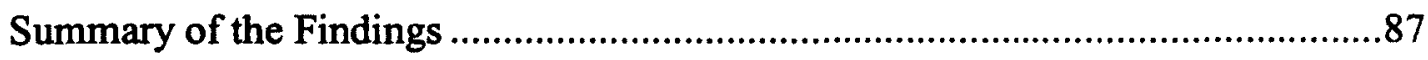

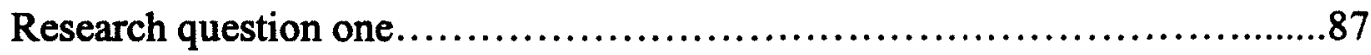

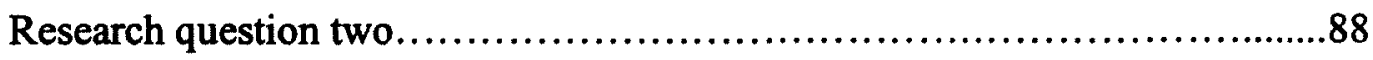

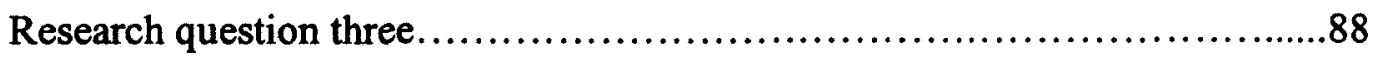

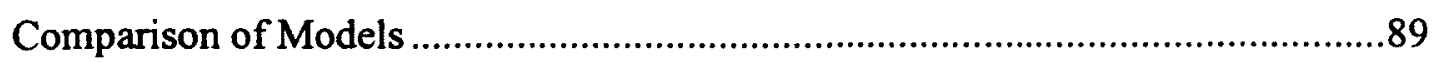

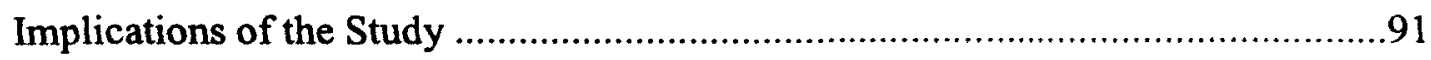

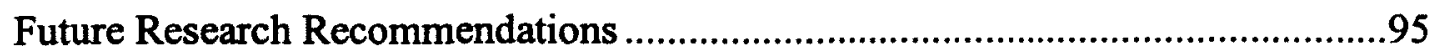

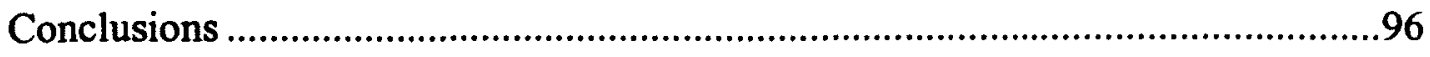

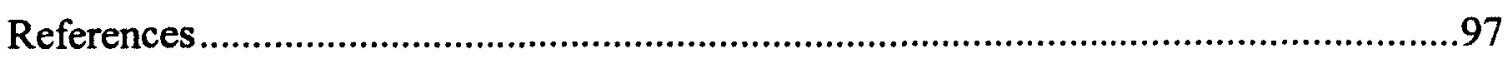

Appendix A Recruitment Email............................................................................... 


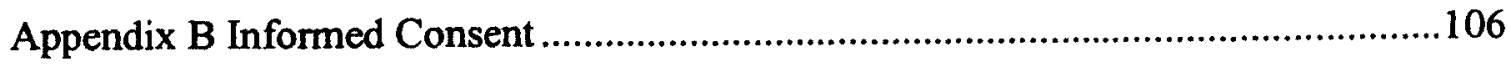

Appendix C Demographic and Narrative Questions .............................................108 


\section{List of Tables}

Table 1. Characteristics Measured Using Intercultural Competency Models .16

Table 2. Quick Reference to Methods and Consideration for Use .18

Table 3. Private Catholic University Participant Demographics .39

Table 4. Private Baptist University Participant Demographics .41

Table 5. Comparison of Theoretical Models. .90

Table 6. Expected Learning Outcomes to Develop Characteristics of ICC .93 


\section{List of Figures}

Figure 1. Seven Characteristics of Intercultural Competency ..................................26

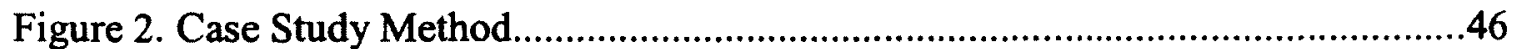

Figure 3. Development of Intercultural Competency ........................................ 81

Figure 4. Comparison of Models.............................................. 


\section{CHAPTER ONE}

Many different groups of sojourners have been identified, including tourists, businesspeople, missionaries, students, and advisers visiting other cultures or reentering their own culture. In the past 50 years, much has been learned about improving intercultural contact so that people could be both more effective in their collaborations and more curious about each other (Triandis, 2004, p. ix).

Brown (2008) defined globalization as a growing interconnection between people, nations, cultures, governments, environments, economies, and indeterminate global networks. Globalization has created greater complexity for those leading and managing organizations. The problem, according to Hofstede and Hofstede (2004), is that globalization increases the need to understand the impact of diverse backgrounds and philosophies of people from different cultures. Wibbekie (2009) concurred, and explained that the greatest challenge facing leaders in this era of globalization is knowing how to work through cultural barriers, and adds that leaders must work across national and cultural boundaries to achieve goals and objectives.

As globalization increases, institutions and organizations are seeking individuals that are interculturally competent and prepared to lead for the $21^{\text {st }}$ century. Specifically, researchers have pointed to intercultural competency (ICC) as the primary leadership practice needed by individuals (Chin, Gu \& Tubbs, 2001; Sheridan, 2005; Treverton \& Bikson, 2003; Wibbeki, 2009) but defining intercultural competency and actually identifying the characteristics required to be interculturally competent is somewhat problematic given the conflicting views and definitions. For the purposes of this study, ICC is defined by the seven characteristics found in the literature (Corbitt, 1998; Kelly \& Meyers, 1995; Mercedes \&Vaughn, 2007; Sheridan, 2005; Williams, 2005). They 
include: (a) The ability to interact with people of different cultures, (b) Awareness of one's own cultural worldview and having an awareness of other's worldview, (c) Attitude towards cultural differences, (d) Knowledge of different cultural practices and worldviews, (e) Cross-cultural skills, (f) Change in behavior when interacting with people from different cultures, and (g) Values relationships with people from another culture.

Regardless of the varying terms such as cross-cultural competence, global competence, and global citizenship and varying conceptualizations of ICC, researchers have agreed that higher education institutions need to develop competencies that go beyond an individual's home country or culture (Morrison, 2000; Cheng \& Zhao, 2006; King \& Howard-Hamilton, 2003; Castellanos, Gloria, Mayorga \& Salas, 2007). Scholars have suggested many ways to develop ICC, such as internationalizing the curriculum (Deardorff, 2004; Raby, 2007; Stearns, 2009) and cultural immersion, which means becoming immersed in the culture firsthand (Deardorff, 2006; Sheridan, 2005) as the best ways for individuals to become more aware of different cultures. Specifically, in higher education, Stearns (2009) suggested that courses need to have an international focus, students must engage with international students and visiting international scholars, and study abroad to gain a better global understanding.

Tye (2003) stated that the purpose of studying abroad is to "learn about problems and issues which cut across national boundaries and about the interconnectedness of systems - cultural, ecological, economic, political, and technological" (p. 113). Study abroad programs range from short-term to long-term programs. Although there seems to be agreement that long-term study abroad programs are typically one semester (16 
weeks) or more (Engle \& Engle, 2003), there is still some confusion on how to define short-term study abroad programs. Long, Akande, Purdy and Nakano (2010) defined short-term programs as two weeks to three months; whereas, other scholars such as Donnelly-Smith (2009) and Gordon, Heischmidt, Sterrett, and McMillian (2009) defined short-term programs as fewer than eight weeks, or ranging from one to four weeks, respectively.

One might assume that studying abroad for a longer period of time would enhance students' intercultural competency; however, there is no evidence to prove that longer is better. Paige, Fry, Stallman, Josic and Jon (2009) found that "duration of stay is insignificant in terms of the degree to which students who study abroad are globally engaged" (p. 12). Moreover, a study from the University of Minnesota (Malmgren \& Galvin, 2008) found no significant difference in global engagement (defined as degree of international and domestic civic commitment and volunteerism) between students who had studied for longer (one semester or more) or shorter periods (less than one semester).

Scholars have found many benefits to studying abroad such as developing transferable workplace competencies (Hofstede, 2001; Steglitz, Gardner \& Gross, 2009) and promoting global leadership (Chin, Gu \& Tubbs, 2001; Early, Ang \& Tan, 2006; Harris, Moran \& Moran, 2007; Tubbs \& Schulz, 2006). Global leadership has been used to indicate a geographic location (i.e. where leadership takes place), universally accepted culturally endorsed leadership traits (i.e. GLOBE ${ }^{1}$ project), and as an adjective to distinguish a particular way of doing leadership (Lokkesmoe, 2009). However, promoting global leadership is not enough. Institutions must prepare individuals to be interculturally

1 Global Leadership and Organizational Behavior Effectiveness (GLOBE) research program identified nine cultural dimensions (House \& Javidan, 2004). 
competent for our globalized society. Therefore, it is imperative to identify what characteristics of ICC can be developed through study abroad programs to prepare global leaders for the $21^{\text {st }}$ century.

In this study, I explored how 14 graduate students at two different institutions who are enrolled in a leadership studies program defined their ICC as a result of a shortterm study abroad course. Specifically, I investigated whether or not participants identified the seven characteristics (ability, attitudes, awareness, behaviors, knowledge, skills, and values) of ICC identified in the literature and affirmed in my pilot study. In addition, I examined what factors facilitated or constrained students to develop ICC.

\section{Background to the Study}

According to the Institute of International Education (2008), more than half of all American students (graduate and undergraduate students) who studied abroad in the 2006-2007 academic year (55.4\%) participated in short-term programs, compared to only $3.3 \%$ during the 1996-97 academic year. The recent growth in short-term study abroad programs has increased the need to gather data about study abroad outcomes (Deardorff, 2004; Engle \& Engle, 2003; Stearns, 2009) yet, to date there is a concerning lack of empirical evidence regarding the merits of short term study abroad programs (Hett, 1993; Kehl \& Morris, 2007). One of the primary challenges in gathering data has been the varying lengths of study abroad programs across institutions, which makes it difficult to determine if intercultural competencies can be developed through these opportunities. Moreover, there is limited research available on the impact of short-term study abroad programs on graduate students, even though graduate student participation in study abroad programs has increased over the last five years by an additional 34,000 students 
(Institute of International Education, 2010). In addition, there is limited research on shortterm study abroad learning outcomes (Chieffo \& Griffiths, 2004), even though the data from the Institute of International Education suggests an increase in short-term study abroad participation.

Professionals in international education are currently struggling with how to develop ICC through short-term programs. The University of Delaware's Center for International Studies (Chieffo \& Griffths, 2004) embarked on the institution's first-ever study abroad assessment to determine whether undergraduate students taking short-term study abroad courses (at least four weeks in length) acquire "global awareness." Global awareness was defined by four categories: intercultural awareness, personal growth and development, awareness of global interdependence, and functional knowledge of world geography and language.

We know from this, the only large-scale (over 2,300 respondents) assessment on a short-term study abroad program, that undergraduate students who spent one month abroad were more confident in their levels of intercultural awareness and functional knowledge than the control group that did not study abroad. However, this selfassessment survey only measured perceived learning outcomes from undergraduate students rather than actual learning outcomes. There have been four recent studies that attempted a pre-post design to measure actual learning outcomes, but one study only had 16 participants, which did not yield significant results (Anderson, Lawton, Rexeisen, \& Hubbard, 2006), and the other three studies were used to measure the improvement of language skills of participants and not intercultural competencies (Engle \& Engle, 2004; Medina-Lopez-Portillo, 2004; Paige, Cohen, \& Shively, 2004). 
As organizations increasingly rely on higher education institutions to create interculturally competent individuals by way of culture immersion, it is imperative to have a deeper understanding of participants' ICC development as a result of a short-term study abroad program. Although Lindsey (2005) reported that undergraduate students benefit in many ways such as increased commitment to peace and international cooperation, greater interest in transnational affairs, and greater emphasis on international understanding, to name a few, we have not yet learned what the benefits are for graduate students, if any. In addition, there is a growing need to gather data about short-term study abroad outcomes among graduate students since studying abroad for longer periods is not always an option due to financial and personal obligations (Buczynski, Lattimer, Inoue \& Alexandrowicz, 2010; Edmonds, 2010).

\section{Statement of the Problem}

Several studies have examined the impact of study abroad programs at the undergraduate level, with a specific focus on long-term study abroad programs. While multiple studies discuss the advantages of long-term study abroad programs such as increased levels of intercultural communication, cross-cultural adaptability, cross-cultural sensitivity (Williams, 2005), and foreign language acquisition (Dwyer, 2004), there is limited research available on the impact of short-term study abroad programs for graduate students.

To date, studies have found undergraduate students who participated in short-term study abroad programs to be more confident in their levels of intercultural awareness and functional knowledge (Chieffo \& Griffiths, 2004) and to have a greater appreciation for diverse cultures, and enhanced awareness pertaining to their own culture (Anderson et al., 
2006). Although short-term study abroad programs are growing, there is a lack of scholarly research exploring whether or not intercultural competencies can be developed through short-term study abroad programs for graduate students.

Even agreeing on what ICC means is a problem. The literature continues to use varying characteristics to define ICC and has not explored how graduate students define intercultural competencies. In addition, we still do not know what factors facilitate or constrain graduate students from developing ICC.

\section{Purpose of the Study}

The purpose of this study was to investigate the experiences of graduate students who participated in a short-term study abroad program at two different universities and to assess their ICC development. The seven characteristics of intercultural competency (ICC) generated from the existing research on the development of ICC among undergraduate students helped to frame my investigation of the experiences of graduate students. The seven characteristics of ICC found in the literature and described previously are: ability, awareness, attitude, knowledge, skills, behavior, and values (Corbitt, 1998; Kelly \& Meyers, 1995; Mercedes \&Vaughn, 2007; Sheridan, 2005; Williams, 2005).

The results of this study are important for international educators who are developing, planning, and assessing study abroad programs for graduate students. In addition, students interested in developing their ICC will gain a better understanding of the factors that facilitate and challenge their efforts. 
The following research questions guided the study:

1. How do graduate students at two different institutions who are enrolled in a leadership studies program define their ICC as a result of a short-term study abroad course experience?

2. What factors facilitated or constrained students to develop the seven characteristics of ICC?

3. How do we account for the similarities and differences experienced by the participants both within and across the two university programs? 


\section{CHAPTER TWO}

\section{Literature Review}

A careful review of the literature is vital to understanding the varying theoretical frameworks and research contributing to the development of intercultural competencies. Bennett, Bennett and Landis (2004) pointed out in the Handbook of Intercultural Training that researchers and practitioners have introduced theory, research, and training to develop effective intercultural interactions. As a result, different disciplines ranging from anthropology, psychology, education, and business have coalesced intercultural relations into effective approaches to train for "intercultural competence" (p. 2). However, "intercultural competence" is not a universal term.

There is some confusion about what intercultural competencies are, disagreement about the different theoretical models used to assess intercultural competencies, and variation on how an organization prepares an individual to acquire and develop intercultural competencies. All of these factors impact discussions about how organizations can best prepare individuals for a globalized society. Furthermore, competing definitions and conceptualizations of intercultural competency (ICC) make it difficult to create a meaningful outcome assessment (Stearns, 2009).

To begin, in the literature review I will identify similar terms associated with measuring an individual's intercultural competence in a global society. I will explain how the term intercultural competence has been conceptualized and used in a variety of ways, and how studies have identified similar and different characteristics needed for an interculturally competent individual. Next, I will review the different intercultural competency models, which have been used by organizations to assess whether an 
individual is or is not interculturally competent. Finally, I will examine study abroad programs that have been proposed to develop intercultural competency among individuals and support the need to evaluate the effectiveness of short-term study abroad programs used to develop ICC.

\section{Terms Associated with Measuring Intercultural Competency}

An institution must consider the different terms used to measure intercultural competency before they can determine if they have developed intercultural competency. Different terms have different definitions and measure different characteristics. Definitions and characteristics will be discussed later in the paper. First, we need to review how different terms are associated with measuring intercultural competency.

In a Delphi study by Deardorff (2006), administrators who were working in higher education used the following terms interchangeably: cross-cultural competence, global competence, intercultural competence, and global citizenship. This variation causes confusion when educators attempt to educate their students in ways that will prepare them to work with culturally diverse populations, because the different terms may have different definitions. Olson and Kroeger (2001) surveyed 52 university faculty and staff from different academic disciplines and asked, "How can we better educate students in our increasingly diverse society" (p.116)? They found that educators need global, intercultural, and professional development in order to better educate our students. The term "intercultural competency" was never used; instead, faculty and staff from different academic disciplines used terms like global competencies and intercultural communication to identify the characteristics needed of a globally competent educator, but could not define what the terms meant. When preparing future global leaders, it is imperative for educators to know that different terms exist and use the same term and 
definition throughout development and implementation of a program in order to accurately understand what you are measuring, and specifically, what the desired learning outcomes are. For example, there are obvious differences when one attempts to measure intercultural communication versus global competencies.

For the purposes of leadership training in companies, some researchers have also suggested different terms in place of intercultural competency when discussing the ideal characteristics of an interculturally competent individual. For example, Karim (2003) introduced the concept of intercultural consciousness in the context of leadership education, which is different than intercultural competency because it focuses on ethical and moral responsibility. As Karim (2003) described, "organizations that engage with diverse counterparts and customers with the sole purpose of advancing their self-interest at any cost may be interculturally competent, and yet be bereft of intercultural consciousness" (p. 35). Organizations must be made aware of the different terms and be sure that they know that similar sounding terms do not necessarily mean the same thing. Confusion in terms could cause inconsistencies in developing and assessing intercultural competencies, which is why it is important to make the terms and definitions very clear. What is Intercultural Competency?

There are not only competing terms such as cross-cultural competence, global competence, and global citizenship used to talk about intercultural competency, but there are competing definitions and conceptualizations of intercultural competency. A specific and widely accepted definition of intercultural competency is needed in order to achieve meaningful outcome assessment (Boyatzis, 1982; Stearns, 2009). Deardorff (2004) for 
example, used a Delphi method ${ }^{2}$ to determine the top-rated definition from intercultural scholars, and she determined that intercultural competency is "the ability to communicate effectively and appropriately in intercultural situations based on one's intercultural knowledge, skills, and attitudes" (p. 194). Deardorff combined Bennett's definition (2004) on intercultural competency and skills for development to produce the top-rated definition selected by intercultural scholars. Bennett and Bennett's (2004) definition emerged from the social science field of intercultural communication, which states: "intercultural competence is the ability to communicate effectively in cross-cultural situations and to relate appropriately in a variety of cultural contexts" (p. 149). In Deardorff's (2006) later study of administrators in higher education, she found that that the definition most applicable to institutions' internationalization strategies was defined as: "Knowledge of others, knowledge of self; skills to interpret and relate; skills to discover and/or to interact; valuing others' values, beliefs, and behaviors; and relativizing one's self' (p. 247). Bennett and Bennett (2004) argue that knowledge, attitude, and behavior must work together for ICC development to occur.

\section{Intercultural Competency Models}

The challenge to develop a compelling and consistent definition of intercultural competency has fostered a plethora of different theoretical models (Bennett, Bennett \& Landis, 2004). Bennett, Bennett and Landis (2004) point out that there is an increased emphasis on empirical assessment of training through evaluation studies. "This drive

2 The Delphi Method is an established research technique used for gathering expert feedback for distillation (Sheridan, 2005). 
toward measurable outcomes and quantitative data has fostered the development of various valid and reliable inventories" (Bennett et al., 2004, p. 2).

Given this variation, how does an organization know which intercultural competency model to use? Paige (2004) suggests an intercultural model that can "identify, describe, assess, categorize, or evaluate the cultural characteristics of individuals, groups, and organizations" (p. 86). For the purposes of this literature review, a fairly comprehensive analysis of models that measure characteristics at the individual level will be examined. Some models were excluded from the review because they represented a similar purpose or described similar characteristics assessed by other models. While this is not an exhaustive list, it will give the reader some background on the purpose of the model and which characteristics of ICC it is measuring.

An intercultural competency model should be able to assess whether or not ICC was developed. One way to assess effectiveness is by using a model that measures the characteristics that have been identified by the organization as characteristics to develop an interculturally competent individual. Paige (2004) states ten purposes for using models in intercultural training: (a) assessing personal development, (b) analyzing and developing organizations, (c) analyzing audiences, (d) exploring cultural, racial, and ethnic identity issues, (e) demonstrating cultural forms of human diversity, (f) presenting theory and bridging theory to practice, (g) examining topics salient to the training program, (h) overcoming resistance, (i) facilitating data-based training, and (j) varying the training activities.

Intercultural competency models can be multidimensional and serve several purposes or can have a single purpose for an individual or organization. For example, 
Paige (2004) points out that the Intercultural Development Inventory by Hammer and Bennett (1998) is a multipurpose model useful for personal development and selfawareness, audience analysis, examining topics salient to the training program, organizational assessment and development, and data-based intercultural training. On the other hand, the Military Equal Opportunity Climate Survey (Dansby \& Landis, 1991) and the Assessing Diversity Climate (Roizner, 1996) models have a single purpose for organizational assessment (versus an individual assessment) and development. Characteristics of an Intercultural Competent Individual

As discussed in the previous section, there are competing definitions among scholars as to what characteristics make up an interculturally competent individual. In fact, many scholars have surveyed educators and global leaders in an attempt to determine what characteristics make up a culturally competent individual, but scholars have not come to an agreement on these characteristics.

Although the literature generally points to seven characteristics (ability, attitude, awareness, behaviors, knowledge, skills, and values) of ICC, the terms continue to be used loosely without a clear understanding of what they mean. Some scholars have identified awareness of other worldviews, knowledge (history of race relations, economic development of a particular country, or the ability to identify culturally appropriate hostess gifts when invited to someone's home for dinner), and skills (looking at situations from more than one perspective, identifying cultural bias, and using more (or less) direct communication in a specific setting), as the top three characteristics of an interculturally competent individual (Olson and Kroeger, 2001; Mercedes \&Vaughn, 2007; Sheridan, 2005). Conversely, other researchers have found an individual's attitude (toward cultural 
differences), behavior (how an individual interacts with people from different cultures), and values (human relations orientation) toward other cultures to be more beneficial than knowledge and skills (Corbitt, 1998; Kelly \& Meyers, 1995; Williams, 2005).

The literature suggests a self-assessment of the individual characteristics named above to develop intercultural competency. This means that individuals determine if they possess the set of ideal characteristics by answering a series of survey questions. The problem is that data is not always reliable. Self-assessments can be problematic since some people tend to answer how they think they should answer. A body of empirical work documents that most people believe they are above average in a variety of skills and abilities (Zábojnik, 2004). Alternative methods that do not focus on self-assessment should be considered (i.e. journaling, short-answers, or personal interviews).

Of serious concern in assessing ICC is that different intercultural competency models measure different characteristics. Table 1 is a visual representation of the different models used to measure individual characteristics. For example, if the key concept being assessed is world mindedness, which Paige (2004) defined as "positive attitudes toward issues such as immigration, world government, and world economic justice" (p. 113), then the Cross-Cultural World Mindedness Scale (Der-Karabetian \& Metzer, 1992) would provide useful training to measure an individual's attitude. If the focus was exclusively on individual behaviors and knowledge, versus ability, attitude, or skills, then the Cultural Intelligence Scale (Ang et al., 2007) would be most fitting. 
Table 1. Characteristics measured using ICC models

\begin{tabular}{|c|c|c|c|c|c|c|c|}
\hline $\begin{array}{l}\text { Name of Model } \\
\text { (sorted by year) }\end{array}$ & Ability & Attitude & Awareness & Behaviors & Knowledge & Skills & Values \\
\hline $\begin{array}{l}\text { Value Orientation Survey } \\
\text { (Kluckhohn and } \\
\text { Strodtbeck, 1961) }\end{array}$ & & & & & & & $\checkmark$ \\
\hline $\begin{array}{l}\text { Multicultural Awareness- } \\
\text { Knowledge-Skills Survey } \\
\text { (D'Dandrea, Daniels, } \\
\text { Heck, 1991) }\end{array}$ & & & $v$ & & $\checkmark$ & $\checkmark$ & \\
\hline $\begin{array}{l}\text { Cross-Cultural World } \\
\text { Mindedness (Der- } \\
\text { Karabetian \& Metzer, } \\
\text { 1992) }\end{array}$ & & 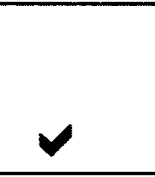 & & & & & \\
\hline $\begin{array}{l}\text { Intercultural Sensitivity } \\
\text { Inventory (Bhawuk \& } \\
\text { Brislin, 1992) }\end{array}$ & & & & & & & $\checkmark$ \\
\hline $\begin{array}{l}\text { Cultural Shock Inventory } \\
\text { (Reddin, 1994) }\end{array}$ & & & $\nu$ & & & & \\
\hline $\begin{array}{l}\text { Cross-Cultural } \\
\text { Adaptability Inventory } \\
\text { (Kelly \& Meyers, 1995) }\end{array}$ & $\checkmark$ & $\checkmark$ & $\checkmark$ & & & $\checkmark$ & $\checkmark$ \\
\hline $\begin{array}{l}\text { Assessing Diversity } \\
\text { Climate (Roizner, 1996) }\end{array}$ & & $\checkmark$ & & & & & \\
\hline $\begin{array}{l}\text { Culture-General } \\
\text { Assimilator (Cushner \& } \\
\text { Brislin, 1996) } \\
\end{array}$ & $\vee$ & & & & & & \\
\hline $\begin{array}{l}\text { Global Awareness Profile } \\
\text { Test (Corbitt, 1998) }\end{array}$ & & & $\checkmark$ & & $\checkmark$ & & \\
\hline $\begin{array}{l}\text { Intercultural } \\
\text { Development Inventory } \\
\text { (Hammer \& Bennett, } \\
\text { 1998) }\end{array}$ & & & $v$ & & & & \\
\hline $\begin{array}{l}\text { Learning Styles Inventory } \\
\text { (Kolb, 1999) }\end{array}$ & & & & & & $\nu$ & \\
\hline $\begin{array}{l}\text { Overseas Assignment } \\
\text { Inventory (Tucker, 1999) }\end{array}$ & & & $\checkmark$ & $\checkmark$ & $\checkmark$ & & \\
\hline $\begin{array}{l}\text { Sociocultural Adaptation } \\
\text { Scale (Ward \& Kennedy, } \\
\text { 1999) }\end{array}$ & & & $v$ & $\checkmark$ & & & \\
\hline $\begin{array}{l}\text { Developmental } \\
\text { Progression Model for } \\
\text { Intercultural } \\
\text { Consciousness (Karim, } \\
2003 \text { ) }\end{array}$ & & & & & & $\gamma$ & \\
\hline $\begin{array}{l}\text { Cultural Intelligence Scale } \\
\text { (Ang \& Van Dyne, 2008) }\end{array}$ & & & & $\checkmark$ & $\checkmark$ & & \\
\hline
\end{tabular}


While at least one of the seven characteristics (ability, attitude, awareness, behaviors, knowledge, skills, and values) appear in the models identified in Table 1, to date, there is not one theoretical model that includes all the seven individual characteristics to assess ICC study abroad courses.

How Do We Develop Intercultural Competency?

There is a growing body of research investigating ways to measure, develop, and assess intercultural competence through study abroad programs (Deardorf, 2005; Flack, 1976; Malmgren \& Galvin, 2008; Paige; 2004; Vande Berg, 2001; Williams, 2005), but relatively little attention has been given to identifying the mechanisms used to develop ICC. Higher education institutions (Cheng \& Zhao, 2006; King \& Howard-Hamilton, 2003; Castellanos et al.; 2007) are viewed as the space most likely to develop ICC but as Fowler and Blohm (2004) claimed, it is more than the experience of going abroad. It is more likely that different teaching methods and the learning styles of the participants play a significant role. Table 2 shows that study abroad (immersion) is only one way to develop ICC, and demonstrates the influence of different teaching methods and learning styles.

Fowler and Blohm (2004) categorize methods that develop intercultural competency into cognitive, active, and intercultural domains. Cognitive methods include such activities as lectures, reading, workbooks, computer-based training, films, selfassessment, case studies, and critical incidents, which focus learners on knowledge acquisition. Active methods include such training as role-playing, simulation games, and intercultural exercises that focus on knowledge, skills, and attitudes. Intercultural methods include such events as contrast culture training, culture assimilator or 
intercultural sensitizer, cross-cultural analysis, cross-cultural dialogues, area studies, and immersion, and these focus on intercultural learning that uses knowledge, skills, and attitudes as learning outcomes.

Table 2. Quick reference to methods and consideration for use (Fowler \& Blohm, 2004)

\begin{tabular}{|c|c|c|c|c|c|}
\hline Methods & Training Outcomes & $\begin{array}{l}\text { About or Across } \\
\text { Cultures }\end{array}$ & Learning Styles & $\begin{array}{l}\text { Useful with } \\
\text { Groups }\end{array}$ & $\begin{array}{l}\text { Useful with } \\
\text { individuals }\end{array}$ \\
\hline Lecture & Knowledge & About Cultures & $\begin{array}{l}\text { Abstract } \\
\text { Conceptualization }\end{array}$ & Yes & Yes \\
\hline Written materials & Knowledge & $\begin{array}{l}\text { About Cultures } \\
\text { primarily }\end{array}$ & $\begin{array}{l}\text { Abstract } \\
\text { Conceptualization }\end{array}$ & Yes & Yes \\
\hline $\begin{array}{l}\text { Computer-based } \\
\text { training }\end{array}$ & Knowledge, skills & About Cultures & $\begin{array}{l}\text { Active } \\
\text { experimentation }\end{array}$ & Yes & Yes \\
\hline Film & $\begin{array}{l}\text { Knowledge, skills, } \\
\text { attitudes }\end{array}$ & Both & $\begin{array}{l}\text { Concrete } \\
\text { experience }\end{array}$ & Yes & Yes \\
\hline Self-assessment & Knowledge & About & $\begin{array}{l}\text { Abstract } \\
\text { Conceptualization }\end{array}$ & $\begin{array}{l}\text { Of } 30 \text { or } \\
\text { fewer }\end{array}$ & Yes \\
\hline Case studies & Knowledge, skills & Both & $\begin{array}{l}\text { Concrete } \\
\text { experience }\end{array}$ & $\begin{array}{l}\text { Of } 30 \text { or } \\
\text { fewer }\end{array}$ & Yes \\
\hline Critical incidents & $\begin{array}{l}\text { Knowledge, skills, } \\
\text { attitudes }\end{array}$ & About Cultures & $\begin{array}{l}\text { Concrete } \\
\text { experience }\end{array}$ & $\begin{array}{l}\text { Of } 30 \text { or } \\
\text { fewer }\end{array}$ & Yes \\
\hline $\begin{array}{l}\text { Simulations and } \\
\text { Games }\end{array}$ & $\begin{array}{l}\text { Knowledge, skills, } \\
\text { attitudes }\end{array}$ & About Cultures & $\begin{array}{l}\text { Active } \\
\text { experimentation }\end{array}$ & $\begin{array}{l}\text { Of more than } \\
10\end{array}$ & \\
\hline Role Play & Skills, attitudes & Across cultures & $\begin{array}{l}\text { Active } \\
\text { experimentation; } \\
\text { concrete } \\
\text { experience }\end{array}$ & Yes & \\
\hline Culture Contrast & Attitudes & Both & All & Yes & \\
\hline \begin{tabular}{|l} 
Culture \\
Sensitizer
\end{tabular} & $\begin{array}{l}\text { Knowledge, skills, } \\
\text { attitudes }\end{array}$ & Both & $\begin{array}{l}\text { Concrete } \\
\text { experience }\end{array}$ & $\begin{array}{l}\text { Of } 30 \text { or } \\
\text { fewer }\end{array}$ & Yes \\
\hline Culture Analysis & Knowledge, skills & About Cultures & $\begin{array}{l}\text { Reflective } \\
\text { Observation }\end{array}$ & Yes & Yes \\
\hline $\begin{array}{l}\text { Cross-cultural } \\
\text { dialogues }\end{array}$ & & Both & $\begin{array}{l}\text { Concrete } \\
\text { experience }\end{array}$ & $\begin{array}{l}\text { Of } 30 \text { or } \\
\text { fewer }\end{array}$ & Yes \\
\hline Area Studies & Knowledge & About Cultures & $\begin{array}{l}\text { Abstract } \\
\text { Conceptualization }\end{array}$ & Yes & Yes \\
\hline Immersion & $\begin{array}{l}\text { Knowledge, skills, } \\
\text { attitudes }\end{array}$ & Both & $\begin{array}{l}\text { Active } \\
\text { experimentation }\end{array}$ & Yes & Yes \\
\hline Exercises & Knowledge, skills, & About Cultures & $\begin{array}{l}\text { Active } \\
\text { experimentation, } \\
\text { concrete } \\
\text { experience }\end{array}$ & Yes & Yes \\
\hline Visual Imagery & Knowledge, attitudes & Both & $\begin{array}{l}\text { Reflective } \\
\text { observation }\end{array}$ & Yes & Yes \\
\hline Art and Culture & $\begin{array}{l}\text { Knowledge, skills, } \\
\text { attitudes }\end{array}$ & Both & $\begin{array}{l}\text { Reflective } \\
\text { observation }\end{array}$ & Yes & Yes \\
\hline
\end{tabular}


Scholars are continually trying to determine if there is one preferred method to develop intercultural competencies. Within higher education, Raby (2007) concurs with Fowler and Blohm (2004) that internationalizing the curriculum with on-and-off campus strategies is the best approach.

On-campus internationalization strategies range from an individual faculty member's efforts to integrate independently gained knowledge into course content to systemic changes that result from purposeful college wide reforms. Off-campus internationalization strategies include education abroad, which embodies study abroad, work abroad, and international internships or volunteer programs. (Raby, 2007, p. 57).

Similarly, Sheridan (2005) asked a group of international researchers and business leaders how individuals can become more aware of different cultures and found that culture immersion (becoming immersed in the culture firsthand) was most effective. Deardorff (2006) agrees that culture immersion (through study abroad) increases students' awareness, but also suggests that institutions implement multiple international efforts such as, faculty international involvement, internationalization of the curriculum, and the creation of joint international co-curricular activities to increase intercultural competency. The problem is that since there is limited research on the effects of these other training methods, scholars continue to reference study abroad as one of the best ways to develop ICC.

Within study abroad program research, there is a growing body of literature investigating the necessary program components and course design (Forum on Education Abroad, 2007; Mills, Deviney \& Ball, 2010). For example, the literature suggests that study abroad programs typically do the following: (a) identifies learning objectives and prepares a course syllabus that provides an academic anchor which helps to set the focus 
for the course; (b) requires pre-trip meetings that involve both faculty and students in areas such as team building, preparation of key sites to visit, and related academic/experiential activities, and expectations regarding behaviors for serving as ambassadors of the university; (c) provides trip implementation that optimizes the use of time to the fullest extent possible to explore historical, political, and cultural attributes of the country and end-of-day group meetings for discussion and self-reflection of the day's activities; (d) prepares for the return trip to the home country and how the events up to this point can be applied to the end-of-trip formal self-reflection paper, and discuss ways the skills and experiences from the program can be related to career goals. Tentative plans for a post-trip meeting within three to five months following the end of the trip can be arranged; and (e) outcome assessment of the trip by the participating faculty can be determined.

In addition to program components, scholars have suggested specific teaching methods for study abroad programs to develop ICC. In a qualitative study by Canfield, Low and Hovestadt (2009), counseling students reported that “personal journaling for self-reflection was useful in integrating their experiential learning with assigned readings in the area of intercultural and multicultural studies" (p. 320). Younes and Asay (2003) found daily group meetings to be the most effective in their study of three international study programs, where discussions and opportunities for self-reflection helped students' process information.

Based on a qualitative study of 11 undergraduate students in the UK, visiting India for 18 days, Scoffham and Barnes (2009) suggested that students engage in pre-trip activities that allow them the opportunity to learn about the historical, political, and 
cultural particularities and interrelationships between countries. Scoffham and Barnes (2009) further suggested that students move through five stages toward ICC: (a) cognitive dimension where students are learning new facts, ideas and concepts; (b) affective dimension, where learning shifts away from the intellectual towards personal and connected knowing, often as part of a shared experience; (c) the existential dimension which consists of deep soul-searching in which students question their values, life purpose, and sense of meaning; (d) the empowerment dimension, which comes about as the students begin to resolve issues and realize that they can make a difference; and (e) the action dimension, which is the final stage in which students realign their lives, either personally or professionally, as a result of their learning.

In summary, different terms, definitions, and theoretical models of ICC have undermined our understanding of how best to support the development of ICC among students, particularly among graduate students. It is imperative, therefore, to determine a deeper understanding of what ICC means to the students themselves. Through a qualitative research investigation of graduate students in two study abroad programs, we are able to gain a better understanding of what ICC means to them and how to develop the characteristics of ICC through university study abroad programs that are intended to support this effort. 


\section{CHAPTER THREE}

\section{Methodology}

A qualitative, comparative case study method was used in this research to explore how doctoral students at two institutions define intercultural competence (ICC) as a result of a short-term study abroad course experience. A case study is a holistic inquiry that investigates a contemporary phenomenon within its natural setting (Yin, 2008). More specifically, Creswell (1998) states, "the context of the case involves situating the case within its setting" (p. 61). Within higher education, scholars have pointed to institutions to develop interculturally competent individuals that are prepared to lead in $21^{\text {st }}$ century society. Institutions claim they are preparing global leaders, either in the design of the curriculum and/or encouraging students to study abroad. Although studying abroad has been found to be one of the best ways to learn about another culture at the undergraduate level, there is no evidence to substantiate that studying abroad can develop ICC among graduate students. Thus, it makes sense to investigate study abroad programs at the graduate level, and more specifically, leadership studies programs that are claiming to prepare our global leaders for the $21^{\text {st }}$ century. The following section will discuss the pilot study that helped to inform this study, the theoretical framework, site selection, data collection procedures, and data analysis.

\section{Preparing for Data Collection}

As institutions and organizations increasingly rely on higher education institutions to prepare individuals to be interculturally competent for our globalized society, it is imperative to identify what characteristics of ICC can be developed through study abroad programs to prepare global leaders for the $21^{\text {st }}$ century. The problem is that there 
continues to be competing definitions among scholars as to what characteristics make up an interculturally competent individual. Of serious concern in assessing ICC is that different intercultural competency models measure different characteristics. While at least one of the seven characteristics (ability, attitude, awareness, behaviors, knowledge, skills, and values) appears as important in each piece of literature reviewed (Ang \& Van Dyne, 2008; Bennett and Bennett, 2004; Bhawuk \& Brislin, 1992; Corbitt, 1998; Cushner \& Brislin, 1996; D’Dandrea, Daniels \& Heck, 1991; Der-Karabetian \& Metzer, 1992; Hammer \& Bennett, 1998; Karim, 2003; Kelly \& Meyers, 1995; Kluckhohn \& Strodtbeck, 1961; Kolb, 1999; Mercedes \& Vaughn, 2007; Olson \& Kroeger, 2001; Reddin, 1994; Roizner, 1996; Sheridan, 2005; Tucker, 1999; Ward \& Kennedy, 1999; Williams, 2005), to date, there is not one theoretical model that has been created to assess ICC change in using all seven characteristics.

Moreover, since there is compelling evidence in the literature to demonstrate that undergraduate students who studied abroad have identified a change in at least one of the seven characteristics of ICC (Chieffo \& Griffths, 2004; Deardorff, 2006), it is important to explore whether or not the same development can occur with graduate students. For this reason, a pilot study was conducted to determine the extent to which any or all seven characteristics found in the literature could be used to help understand graduate students' ICC development.

According to Yin (1994), a pilot case study should be conducted to help prepare a researcher to do a high-quality final case study. It allows the researcher to try different 
data sources (i.e. observations, interviews, document analysis) to increase dependability ${ }^{3}$. I conducted a pilot study in summer 2011 with nine graduate students (Master's level) who studied abroad in Montego Bay, Jamaica for ten days. Convenience and access was the main criteria for selection of participants in this pilot case study. Yin (1994) states that, "convenience, access, and geographic proximity can be the main criteria for selecting the pilot case" (p. 75). Since I sought out to test different methodological approaches (i.e. document analysis, participant observations, and in-depth interviews), it was convenient to conduct a pilot study during the summer when I had time to observe and interview participants while they were abroad. In addition, the instructor for the course granted me permission to travel with the participants and gave me access to pre and post sessions, lectures while abroad, attendance at a professional conference tied to the course, and site visits.

The pilot study provided useful information about the most effective data sources to use for the final case study. I learned that it was very difficult for one researcher to observe nine graduate students while studying abroad, since all nine students were at different places at different times. Time constraints, such as length of time abroad (10 days) and full days scheduled to attend a conference and site visits, made it very difficult to schedule interviews with participants while they were abroad. As a result of the pilot study, I realized that interviews with participants could take place at any time, and did not necessarily have to happen while the students were abroad. Observations and informal interviews with participants helped me to develop relevant questions for the final case

3 Dependability is analogous to the notion of reliability in quantitative research. The purpose of this test is to show indications of stability and consistency in the process of inquiry (Guba, 1981; Riege, 2003). 
study, which will be discussed in further detail under data collection procedures. In addition, I learned from the pilot study that pre and post reflection papers were valuable sources of data since it allows the researcher to code and review data in stable conditions. In other words, reflection papers can be reviewed repeatedly and contain exact names, references, and details of an event (Yin, 1994).

Reflection papers were used to capture participants' assumptions entering the Jamaican culture and to detail the range of experiences and learning attained as a result of the short-term study abroad course (Nash, 2011). I conducted a document analysis by reviewing and coding student pre and post reflection papers using the seven characteristics of ICC found in the literature. In order to establish dependability and transferability ${ }^{4}$, a case study database was created in Excel to organize characteristics and/or themes brought up by the participants in their reflection papers, which would allow me to compare findings between the pilot case study and the final case study. In addition, the case study database would allow other researchers to review the evidence directly rather than solely relying on the written report (Yin, 2003).

Findings from the pilot case study revealed that students in this study abroad program developed ICC along all the seven characteristics that had been identified in the literature. Participants in the pilot study frequently referenced the seven characteristics of ICC as they reflected on their experience before and after studying abroad. As part of the data analysis, I traced how each characteristic of ICC mattered in the participants' development of ICC, which helped me to construct a theoretical model of ICC in a more complex and meaningful way. The data analysis from the pilot study revealed that ICC is

\footnotetext{
4 Transferability is achieved when the research shows similar or different findings of a phenomenon amongst similar or different respondents (Guba, 1981).
} 
an evolving developmental process, as depicted in Figure 1. The pilot study showed that the seven characteristics could be used more confidently as a frame of reference to integrate the data collected on a larger scale.

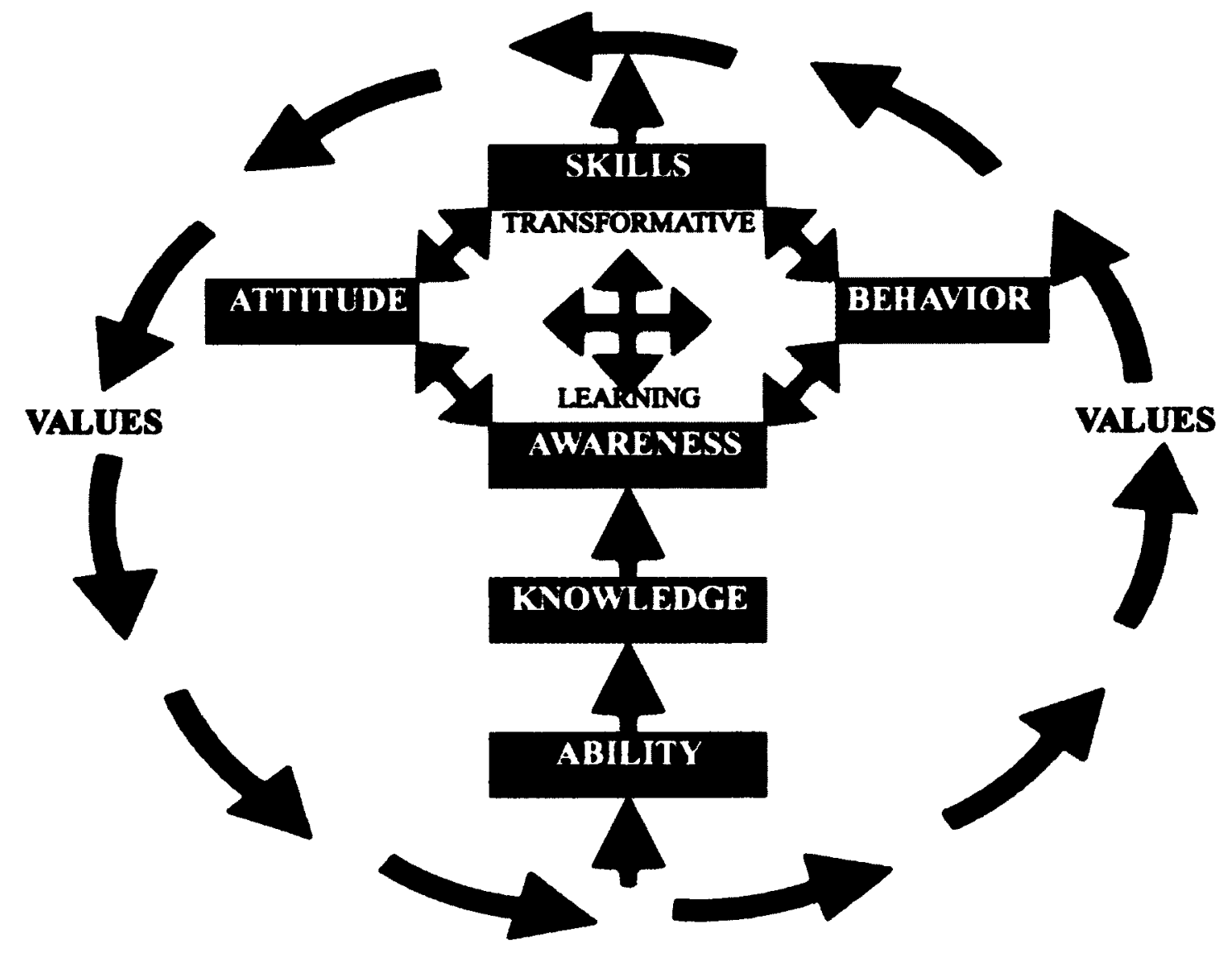

Figure 1. Seven characteristics of ICC

Theoretical Framework

According to Yin (1994), theory development as part of the design phase is essential for case studies, whether the purpose is to develop or to test an existing theory. As discussed in chapter two, there continues to be competing definitions among scholars as to what characteristics make up an interculturally competent individual. While at least one of the seven characteristics (ability, attitude, awareness, behaviors, knowledge, skills, and values) appears as important in the literature (Ang \& Van Dyne, 2008; Bennett \& 
Bennett, 2004), to date, there is not one theoretical model that has been created to assess ICC using all seven characteristics. As discussed previously, I conducted a pilot study to determine the extent to which any or all seven characteristics identified in the literature could be used to help understand ICC development. Findings from the pilot case study validated the use of all seven characteristics of ICC found in the literature, and as a result, I developed a theoretical model to use in examining the data collected from the final case study. I will discuss in the following section how the seven characteristics of ICC are related and graphically depicted in the theoretical model seen in Figure 1.

The nine participants in the pilot study gave evidence in their pre-reflection papers that development of ICC began with an individual's values that were shaped from early childhood (e.g. family, schools, religion, and culture). It was not until the postreflection paper that participants began to re-assess their values as a result of experiencing another culture. Participants indicated that being in a different country pushed them to learn about themselves, question their values, morals, and beliefs, and made them wonder if they imposed their American values on to others. In addition, participants described their feelings as they reflected on their values as "friction" and "frustration" when their values did not seem to align with the values of people around them in another country.

The arrows in Figure 1 depict a moving circle symbolizing the importance of values and how they can change as a person moves through the ICC developmental process. Values make up who a person is, but at the beginning stage in the developmental process, self-assessment of values and how they impact others, may not have necessarily been explored by the individual. Therefore, values as a characteristic of ICC, means more 
than valuing relationships with people from another culture (Mercedes \& Vaughn, 2007). The model developed from the pilot study in Figure 1 suggests that individuals, during their study abroad course, reflect on their values and the impact of the newly identified culture-specific values of the host country on the formation of their own understanding of self (Jun, 2010). This finding was identified as important to the development of ICC and supports the findings from previous research conducted by Jun (2010).

In the pilot study, individuals began to discuss a second characteristic frequently identified in the research on ICC. They expressed the desire to gain an ability to interact with people of different cultures, which was evident in their reflection papers written before going abroad. For the nine participants in the pilot study, ability as a characteristic of ICC was described as having the intent and readiness to immerse themselves in the Jamaican culture. However, the ability (or intent) to immerse oneself in another country did not necessarily translate into gaining the ability to interact with people from different cultures, as suggested by Mercedes \& Vaughn (2007). Participants described ability as the entry point rather than being interconnected to other characteristics. They used skills as an important characteristic of ICC to describe how an individual interacts with people from different cultures. I describe this in more detail below.

Once an individual has the ability to interact with people of different cultures, they seem to be more open to obtain knowledge of different cultural practices and worldviews. Participants in the pilot study acknowledged that their perceptions about Jamaican culture prior to visiting the country was due to their lack of knowledge about the culture and influenced by the media, stereotypes, and/or the "tourist perspective." Students who participated in the Jamaica trip learned about the Jamaican culture through 
required course readings, films, lectures, conference presentations, and immersing themselves in the culture. As a result, post-reflection papers demonstrated that the more knowledge they had, whether it was merely reading pre-course material or actually engaging with Jamaicans, the more they began to explore their personal values and the more they were able to reflect on how their values influence their worldview. The new knowledge obtained through the study abroad course triggered a reflection of values, which is depicted in the circular motion of the arrows, signifying that values surround the entire developmental process. This constant reflection of values when knowledge of another culture is obtained not only shows the factors that supported ICC, but raises the question as to what factors facilitated or constrained students' ICC development along this path.

The pilot study findings indicated that new knowledge obtained about a different culture can give an individual an awareness of a different cultural worldview, as was the case for students studying in Jamaica. During this stage in the process, an individual becomes aware of how their own cultural worldview impacts the culture they are exploring. In their pre-trip reflection, students indicated that they were "aware of being an American" and realized that their knowledge of the Jamaican culture was limited. Their post-reflection papers provided evidence that their awareness of the Jamaican culture was no longer based on stereotypes portrayed by the media and was no longer about merely a place to vacation. The pilot study in general suggested that students experienced an ongoing awareness and exploration of the similarities and differences between cultures. These findings led me to investigate more deeply how participants 
reshape their thinking, understanding, and awareness of another culture as a result of studying abroad.

Up to this point, ability, knowledge, and awareness were described by participants in pre and post-reflection papers as to the characteristics that build upon one another (symbolized by the arrows pointing from one characteristic to the next) and account for the development of ICC. Transformative learning, which Jun (2010) describes as "learning to integrate intellectual understanding with emotional understanding," occurs when awareness causes a shift in attitude, behavior, and/or skills. When there is an awareness of how their own values impact others, awareness can cause a shift in attitude towards cultural differences, and in their behavior when interacting with people from different cultures. The pilot study findings suggested that individuals often go back and forth to different levels of learning between awareness, attitudes, behaviors, and skills during the development of ICC. I have indicated this movement in Figure 1 with double arrows to symbolize how an individual's awareness about another culture can sometimes change attitude and behavior simultaneously, or depending on the individual, can cause a change in attitude and behavior over time. It also shows that ICC development takes knowledge and practice of new cross-cultural skills before a change in attitude and behavior can occur.

Attitude is another characteristic identified as salient to ICC development. It is typically talked about in terms of the shift in understanding of self and others that occurs during study abroad experiences. As a result of the study abroad course to Jamaica, participants reported a deeper understanding of their own identity. For example, 
Samantha ${ }^{5}$ expressed in her pre-reflection paper that she struggled with her own identity being Filipino-American and the labels tied to her as a minority woman. In Samantha's post-reflection paper, she discussed an interaction she had with a young girl from Jamaica who "put a label on her [Samantha] that she did not want, ask for, or expect." As a result of this interaction, Samantha realized that she would now be more conscientious of how others viewed her and how she viewed others. This shift in understanding and attitude of self and others motivated an investigation as to whether or not this same shift would occur with graduate students who are enrolled in a leadership studies program claiming to develop students' ICC.

Behavior was discussed as another characteristic of ICC. It refers to the shift in how an individual acts as a result of developing awareness and knowledge about another culture. Melissa reflected on her study abroad experience in Jamaica and recognized that her awareness changed her behavior:

I became much more aware of what it meant to actually integrate the things that we learn instead of just having the knowledge...I applied this as we rode on our tour bus, went out to the bar, or spent time in the community. I saw myself checking my cognitive processes because of what I had learned. (Melissa)

Melissa's example demonstrates how new knowledge about a culture developed an awareness that caused a shift in her behaviors. However, Melissa also pointed out in her reflection paper that she would revert back to her old way of thinking and acting at times in Jamaica. It was not until her classmates pointed this out that she realized what she was doing. Reflecting on that experience,

$5 \quad$ Pseudonyms were given to all participants in this study to protect their identity. 
Melissa wrote, "Now I need to learn how to catch those thoughts and behaviors myself."

Jun (2010) explained, "The emotional component of transformative learning means that it cannot be hurried. It takes time to process complex emotions, desires, wants, and shoulds"(p. 11). Therefore, it is important to note that a shift in behavior did not occur among all participants in the pilot study. It may have been that a change in behavior was not experienced because the time abroad was short in length (10 days), they simply did not provide examples in the post-reflection paper, or the necessary factors that would support their transformation were not in place. The pilot study demonstrated that pre and post-reflection papers do not provide enough data to understand what changes of behaviors occurred and why or why not.

Cross-cultural communication and thinking styles were found to be important skills for developing ICC. For example, the study abroad participants learned to explore their interpersonal and intrapersonal communication styles as a result of the course and were taught how to change their thinking styles, specifically the dichotomous, hierarchical, linear, diunital, or holistic, multilayered or multidimensional ${ }^{6}$ styles discussed by Jun (2010). In addition, awareness of cross-cultural skills were found to initiate a change in participants' attitudes toward cultural differences. The pilot study suggests that courses can provide students with important skills and new knowledge to change attitudes.

$6 \quad$ Thinking styles were taught to participants as part of the course topic on Multicultural Counseling. Refer to Social Justice, Multicultural Counseling and Practice (Jun, 2010) for complete descriptions of thinking styles. 
Transformative learning is the stage in development of ICC when awareness triggers attitudes, behaviors, and skills. The participants' responses from the pilot study suggested that transformative learning is a process within a process. In other words, an individual can stay in the transformative learning stage for some time, and development of attitudes, behaviors, and skills may not necessarily occur while abroad. Transformative learning, however, occurred among some individuals as indicated by the responses of the students in this pilot study, which warrants further exploration.

After reviewing the nine pre and post-reflection papers from the pilot study, there is compelling evidence that graduate students experienced a change in at least one of the seven characteristics of ICC (ability, attitude, awareness, behavior, knowledge, skills, and values), as a result of their study abroad experience to Jamaica. The greatest development was seen in the participant's awareness of their own cultural worldview, an awareness of the Jamaican culture, and having more knowledge about the Jamaican culture. Additionally, the course provided a platform for the participants to examine the values they were born into and to reflect on the impact of culture-specific values on the formation of their own understanding of self and the Jamaican culture.

The findings from this pilot study were helpful in framing and guiding this more comprehensive investigation and supported using all seven characteristics to assess the development of ICC in the graduate student population recruited for this study. The data analysis also revealed that ICC was an evolving developmental process, as depicted in Figure 1. Although the characteristics of ICC were presented individually and as stages in the developmental process, the characteristics were not found to be mutually exclusive. In fact, some characteristics of ICC (i.e. ability, knowledge, and awareness) were found to 
actually trigger one another in the developmental process. Given the pilot study's limited data analysis (only examining pre and post-reflection papers from nine graduate students in one Master's level class), it seemed important to investigate the use of multiple data sources to explore ICC development among doctoral students who participated in various study abroad programs. Moreover, it was important to test whether or not the same theoretical model of ICC explained the experiences of graduate students enrolled in a leadership studies program claiming to prepare global leaders.

\section{Site Selection}

In order to investigate leadership studies programs that are claiming to prepare our global leaders for the $21^{\text {st }}$ century, a list of institutions awarding doctoral degrees in the United States was downloaded from the International Leadership Association Directory of Leadership Programs (http://www.ila-net.org/Resources/LPD/index.htm last updated on August 20, 2011). Criteria used for the search were: (a) Degree Level (Ph.D. and Ed.D., Ed.S, EdM was selected from the drop-down menu); (b) Country (USA); (c) Delivery Method (Classroom); and (d) Degree Name Keyword (Leadership). The search criteria yielded 41 institutions. The original list of 41 was reduced to 40 due to a duplicate listing. Then, the list of 40 institutions was filtered down to 31 , since nine degree programs no longer had an emphasis in leadership when university websites were searched (e.g. "Higher Education Administration" versus "Education Leadership").

From the filtered list of 31 institutions, university websites were searched to generate a list of study abroad options for graduate students in a leadership program. Programs with study abroad options were chosen because they theoretically are designed to immerse students in a culture firsthand, which is reported to be one of the best ways 
for individuals to develop ICC (Deardorff, 2006; Sheridan, 2005). Eighteen universities did not list or link to any study abroad options on their department website. Of the 13 institutions remaining, 11 doctoral programs made no mention of study abroad options on the leadership program website; however, graduate study abroad was listed as an option for "select programs" on the university study abroad websites. Only two degree programs (Ph.D. in Leadership Studies at Private Baptist University and Ph.D. in Leadership Studies at the Private Catholic University) require an international experience as part of the degree requirements.

Unique purposeful sampling. I used purposeful sampling for this study because as Patton (2002) points out, these "Cases for study are selected because they are 'information rich' and illuminative, that is, they offer useful manifestations of the phenomenon of interest" (p. 40). Although leadership studies programs across the United States claim they are preparing global leaders for the $21^{\text {st }}$ century, Private Catholic University, School of Leadership and Education Sciences and the Graduate School of Leadership Studies at Private Baptist University prove to be unique case studies since they are the only doctoral leadership programs in the United States of America to require an international experience (e.g. short-term study abroad program). Given that studying abroad has been found to be one of the best ways to develop ICC among undergraduate students, there is a need to explore how ICC is defined at the graduate level. The comparative case study allowed for an examination of the characteristics of ICC development (commonalities and differences) across cases, and to understand how their ICC development was similar or different from the characteristics identified as salient to ICC both from the research and from the pilot study conducted with undergraduates. 
Once approval to conduct research at PCU was received through their Institutional Review Board, a recruitment email (see Appendix A) was sent to 12 doctoral students who were currently enrolled at PCU and who had participated in a short-term study abroad course through the PCU Department of Leadership Studies between September 2008 and August 2011. Nine students from PCU responded and agreed to participate in the study. However, one student responded that she was busy and we could not find a day/time to schedule an interview. As a result, eight students from PCU were interviewed for the study.

Once approval to conduct research at PBU was received through their Committee for Protection of Human Participants, the director of Leadership Studies at PBU sent the recruitment email to approximately 70 doctoral students who participated in the summer institute to Oxford, England (J. Dutschke, personal communication, January 8, 2012). Four students from PBU responded to the initial email. Two of the four participants from PBU sent a follow up email to their specific cohort to recruit additional participants. As a result, three additional students volunteered to participate in the study; however, one student noted that he traveled extensively for business and may not have the time. Six students were interviewed from PBU for the study.

Site Descriptions

Profile of Private Catholic University (PCU). PCU is a private, not-for-profit, four-year, doctoral/research university located in California. According to the Institute of International Education (2011), PCU ranks first among national doctoral universities for undergraduate study abroad participation. The Ph.D. in Leadership Studies is one of three doctoral programs offered through the university. According to doctoral student profiles, 
the Ph.D. in Leadership Studies current enrollment is 82 students (SOLES, 2011a). From

Fall 2008 to Summer 2011, 14 doctoral students in leadership studies participated in a short-term study abroad course offered through PCU (Martinez, 2011).

In the Fall of 2008, the School of Leadership at Private Catholic University began requiring all doctoral students to complete an international experience as part of their studies. An international experience can be met through either credit or non-credit experiences. Examples of meeting the requirement include, but are not limited to: enrolling in an " $\mathrm{T}$ " Designated course (an international component is embedded in the course), study abroad offerings by the PCU graduate study abroad office ${ }^{7}$, conducting an applied project with an international organization, participating in an international internship, systematic language study, participating in international speaker events, or conducting a research abroad project approved by the department (SOLES, 2011c).

Since its inception in September 2008, PCU Department of Leadership Studies has offered nine short-term study abroad courses to four different countries: Guatemala, Spain, Qatar, and Canada. Since the Fall of 2008, 391 graduate students (377 Master students and 14 Doctoral students) have chosen to participate in the short-term study abroad course option offered through the PCU graduate study abroad office. For doctoral students, this means that $15 \%$ of those currently enrolled have selected to participate in a short-term study abroad course (Martinez, 2011).

A variety of courses have been offered by the faculty from Leadership Studies, Counseling, Learning and Teaching, and Marital and Family Therapy, which have ranged

$7 \quad$ PCU graduate study abroad office contributes to the education of graduate professionals who engage other cultures, are sensitive to commonalities and differences among and within cultures, understand multiple perspectives and the impact of global transformations, and are committed to positive change (SOLES, $2011 \mathrm{~b}$ ). 
from five to ten days. Between Fall 2008 and Summer 2011, the Leadership Studies department offered the following faculty led courses:

- EDLD 535: Models of Participatory Leadership (Mondragón, Spain)

- EDLD 579: Student Affairs and Higher Education Leadership in Qatar (Doha, Qatar)

- EDLD 579P: Nonprofits and Civil Society in Guatemala (Antigua, Guatemala)

- LEAD 579: Leading and Learning in Cree Culture : A Study Tour to Blue Quills First Nations College and the Surrounding Reserve In Alberta, Canada 
Table 3. PCU participant demographics

\begin{tabular}{|c|c|c|c|c|c|c|}
\hline $\begin{array}{l}\text { Participant } \\
\text { Name }\end{array}$ & Gender & Age & $\begin{array}{l}\text { Self Identified } \\
\text { Ethnicity }\end{array}$ & $\begin{array}{l}\text { Country } \\
\text { Abroad }\end{array}$ & Term & Travel Experience \\
\hline Benjamin & Male & 35 & Asian/Chinese & $\begin{array}{l}\text { Guatemala } \\
\text { and } \\
\text { Mondragón }\end{array}$ & $\begin{array}{l}\text { Intersession } \\
2010 ; \\
\text { Summer } \\
2010\end{array}$ & China \\
\hline Hope & Female & 29 & Caucasian & $\begin{array}{l}\text { Guatemala } \\
\text { and } \\
\text { Mondragón }\end{array}$ & $\begin{array}{l}\text { Intersession } \\
2011 ; \\
\text { Summer } \\
2011\end{array}$ & $\begin{array}{l}\text { Europe, Africa, } \\
\text { Central America, } \\
\text { Indonesia }\end{array}$ \\
\hline Mark & Male & 38 & $\begin{array}{l}\text { Asian- } \\
\text { American }\end{array}$ & Mondragón & $\begin{array}{l}\text { Summer } \\
2011\end{array}$ & $\begin{array}{l}\text { Africa, Europe, } \\
\text { South America, } \\
\text { North America }\end{array}$ \\
\hline Mary & Female & 64 & Caucasian & $\begin{array}{l}\text { Guatemala } \\
\text { and Canada }\end{array}$ & $\begin{array}{l}\text { Summer } \\
2009 ; \\
\text { Summer } \\
2011\end{array}$ & $\begin{array}{l}\text { East Africa, } \\
\text { Romania, France, } \\
\text { England, Scotland, } \\
\text { Whales, Madagascar }\end{array}$ \\
\hline Isabel & Female & 38 & $\begin{array}{l}\text { Portuguese- } \\
\text { Mexican }\end{array}$ & Canada & $\begin{array}{l}\text { Summer, } \\
2011\end{array}$ & $\begin{array}{l}\text { Portugal, Brazil, } \\
\text { Spain, } \\
\text { Italy, Germany, } \\
\text { China }\end{array}$ \\
\hline Abraham & Male & 31 & Vietnamese & Mondragón & $\begin{array}{l}\text { Summer } \\
2011\end{array}$ & $\begin{array}{l}\text { Vietnam, China, } \\
\text { Mexico, Europe, } \\
\text { Belgium, Costa Rica }\end{array}$ \\
\hline Emma & Female & 36 & $\begin{array}{l}\text { Mexican- } \\
\text { American }\end{array}$ & Mondragón & $\begin{array}{l}\text { Summer, } \\
2010\end{array}$ & $\begin{array}{l}\text { Europe, Portugal, } \\
\text { Germany, Austria, } \\
\text { Hungary, Slovakia }\end{array}$ \\
\hline Andrew & Male & 33 & Caucasian & $\begin{array}{l}\text { Qatar and } \\
\text { Mondragón }\end{array}$ & $\begin{array}{l}\text { Summer, } \\
2010 \\
\text { Summer } \\
2011\end{array}$ & England, Germany \\
\hline
\end{tabular}

As can be seen in Table 3, four females and four males who participated in the international study abroad courses agreed to participate in this study. The average age of the participants was 38 years old. The ethnic backgrounds were diverse; three Caucasian, 
three Asian, and two Hispanic ${ }^{8}$. One participant studied in Qatar, one in Canada, three in Mondragón and three students participated in two study abroad courses: two to Guatemala and Mondragón and one to Guatemala and Canada. All participants had traveled outside of the United States at least once prior to traveling through PCU and several have had considerable travel experience to Africa, Asia, and Europe.

Profile of Private Baptist University (PBU). Private Baptist University is a private, not-for-profit, 4-year University located in Texas. All students pursuing a doctorate in leadership studies at PBU are required to participate in three consecutive summer institutes with their cohort. Summer institutes range from 7-14 days. Students spend the first summer institute in Dallas and focus on their personal growth and adult development. During the second summer institute, students travel to Washington D.C. and study political leadership. The third summer institute is spent in Oxford, England. The course in Oxford, England is specifically focused on global and cultural leadership (GCGSL, 2011b).

Between August 2006 and August 2011, there have been six cohorts of approximately 11 to 12 students ( 70 total students) who have completed the three summer institutes (J. Dutschke, personal communication, January 9, 2012). Eight percent of the total students volunteered for this study. At least one person from every cohort since 2006 is represented in this study, except for summer 2009.

As can be seen in Table 4, five males and one female participated in the study. The average age was 49.3 years old. Five participants were Caucasian and one identified

$8 \quad$ Although an analysis of gender and ethnicity are not within the scope of this study, it does provide an opportunity for additional research (see Chapter 5). 
as Caucasian/Hispanic. All participants have traveled at least once prior to traveling to Oxford, England.

Table 4. PBU participant demographics

\begin{tabular}{|l|l|l|l|l|l|}
\hline $\begin{array}{c}\text { Participant } \\
\text { Name }\end{array}$ & Gender & Age & \multicolumn{1}{|c|}{$\begin{array}{c}\text { Self Identified } \\
\text { Ethnicity }\end{array}$} & Term Abroad & \multicolumn{1}{|c|}{ Travel Experience } \\
\hline Elijah & Male & 58 & Caucasian & Summer, 2008 & $\begin{array}{l}\text { Rio de Janeiro, Sao Paolo, } \\
\text { Brazil, Europe }\end{array}$ \\
\hline John & Male & 63 & Caucasian & Summer, 2007 & $\begin{array}{l}\text { London, Scotland, Ireland, } \\
\text { Canada, France, Germany, } \\
\text { Italy, Holland, Switzerland, } \\
\text { Mexico, Brazil, Central } \\
\text { America }\end{array}$ \\
\hline Jordan & Male & 54 & Caucasian & Summer, 2006 & Mexico, Tanzania \\
\hline Francis & Male & 35 & Caucasian & Summer, 2008 & $\begin{array}{l}\text { Guatemala, Hong Kong, } \\
\text { Japan, London, Mexico }\end{array}$ \\
\hline Christopher & Male & 38 & Caucasian & Summer, 2011 & France, Columbia, Thailand \\
\hline Elizabeth & Female & 48 & Caucasian/Hispanic & Summer, 2010 & Mexico \\
\hline
\end{tabular}

\section{Data Collection Procedures}

Given the limited data I was able to collect from the pilot case study conducted in summer 2011 (only pre and post reflections), I designed this study to include multiple sources of information as suggested by Cresswell (1998) and Yin (2008). I utilized three sources of information for this comparative case study: (a) Archival Records; (b) Document Analysis; and (c) Interviews. Use of multiple data sources in the data collection phase, such as triangulation of interviews, documents, and archival records, 
protects against researcher bias (Riege, 2003). In addition, triangulation of data sources is a case study technique for establishing confirmability ${ }^{9}$ and credibility ${ }^{10}$ (Guba, 1981).

Archival records. Yin (2003) differentiated between public or archival records and personal documents. Archival records are those documents that can reveal specifics of the program that cannot be observed. Patton (1980) suggested all correspondence from and to program staff, financial and budget records, organizational rules, regulations, memoranda's, charts and any other official or unofficial document generated by or for the program. I reviewed department websites at Private Catholic University (PCU) and Private Baptist University (PBU) to identify archival records, including, but not limited to: annual reports, department policies on short-term study abroad programs, study abroad handbooks, course syllabi, and assessment reports. Archival records that were generated from the departments regarding the short-term study abroad program were examined.

Document analysis. I collected pre and post reflection papers in this study. Although clearly limited in their ability to provide all of the information I needed, the findings from the pilot study indicated that personal reflections written before and after the short-term study abroad classes were valuable data sources to understand preconceptions of the participants as they began their experience with the study abroad course and to capture the range of experiences and learning outcomes attained from the program. Merriam (1998) supported the value of such data and argued that documents

\footnotetext{
9 Confirmability is analogous to the notion of neutrality and objectivity in positivism, corresponding closely to construct validity. This assesses whether the interpretation of data is drawn in a logical and unprejudiced manner.

10 Credibility is the parallel construct to internal validity. It involves the approval of research findings by either interviewees or peers as realities may be interpreted in multiple ways (Guba, 1981; Riege, 2003).
} 
written by an individual including diaries, letters, home videos, photo albums, autobiographies, and travel logs can be of enormous help in understanding the inner experiences of the participants.

In addition to collecting and analyzing this data, I collected photos, blogs, or additional documents created during or after the study abroad experience from the participants. According to Merriam (2009), "Personal documents are a reliable source of data concerning a person's attitudes, beliefs, and view of the world" (p. 143).

Semi-structured interviews. Although quantitative instruments make it possible to measure the reactions of many respondents to a set of questions at a time, qualitative interviews offer a method for capturing and reporting a more-in-depth understanding and a richer picture of participants' experiences and learning outcomes, leading to a more indepth understanding of the phenomena under study (Patton, 2002). In order to understand what it means for graduate students to be interculturally competent, and to account for other experiences that may not be identified through a quantitative survey, semistructured interviews of graduate students participating in a short-term study abroad course were used to capture the range of experiences and learning outcomes attained.

This study employed a combination of informal conversational interviews and standardized open-ended interviews. Conversational interviews offer flexibility to pursue information based on what emerges from talking with individuals in the immediate context (Patton, 2002). Patton (2002) stated that standardized, open-ended interviews attempt to minimize variation across interviews by using "a set of questions carefully worded and arranged with the intention of taking each respondent through the same sequence and asking each respondent the same questions with essentially the same 
words" (p. 342). The purpose of the interviews were to learn how students define ICC, how and why participants believe they demonstrate characteristics of ICC, to determine whether or not ICC was developed as a result of teaching methods utilized for the study abroad course (and if not, why). It was important to maintain credibility of the study by asking participants the same set of questions, but to be flexible and to allow questions to be generated from the respondent's answers in order to deepen the conversation based on individual experiences. As part of the interview protocol (see Appendix C), the theoretical model created as a result of pilot study was shared (in-person, SKYPE screen sharing, or over email) with the participants after the open-ended interview questions were asked, to determine if the theoretical model created as a result of the pilot study was transferable to the participants in this study. A pilot interview with someone not in the sample but who has participated in a short term study abroad program was conducted before I began my interviews to ensure that questions were clear, concise, effective, and understandable.

Interview procedures. 14 participants (8 from PCU and 6 from PBU) signed an informed consent form prior to participation in the interviews (see Appendix B). Interviews were conducted by participant preference (in-person, SKYPE, or over the phone) to accommodate participants' schedules. Each interview lasted approximately 60 to 90 minutes. The option of participating in one voluntary follow-up interview lasting no more than 60 minutes was requested in cases where clarification of the initial interview was needed. All interviews were tape recorded and transcribed verbatim. Participants were asked to consent to the recording process before the interviews began. Once the 
interview process was complete, participants were contacted, if there was anything unclear in the recordings.

Data Analysis

According to Merriam (2009), data collection and data analysis should be a simultaneous process in qualitative research. Data analysis can occur while in the process of collecting data, as well as between data collection activities. In this study, I began data analysis as soon as I collected archival documents on each site. I read, made notes in the margins, wrote reflections, and developed tentative themes, hunches, ideas, and questions to further explore from this set of data to the next set of data collected throughout the study. I engaged in a continuous process of analyzing data and comparing archival data and document analysis with interview transcriptions from each participant. All notes and themes were stored in a case study database created in Excel during data collection and data analysis to establish dependability and transferability.

Glesne (1999) recommended major code clumping to create an organizational framework that allows the researcher to break major codes down into sub-codes. Based on a review of the literature (Canfield, Low \& Hovestadt, 2009; Fowler \& Bloom, 2004; Scoffham \& Barnes, 2009; Younes \& Asay, 2003), and the developmental model of ICC created in the pilot study, data was coded into the seven characteristics of ICC (ability, attitude, awareness, behaviors, knowledge, skills, and values) and put into additional code categories as they emerged.

I constantly interrogated the data. For example, I asked if archival documents, such as program handbooks or department websites, explicitly state a mission or goal designed to develop any of the seven characteristics of ICC, or, do they point to other 
important themes? To what extent do archival documents, such as annual reports or assessments give evidence that any of the characteristics (or new characteristics) of ICC were developed as a result of the short-term study abroad experience?

Miles and Huberman (1994) and Yin (2003) suggested that data from two cases be analyzed independently and then compared to understand the dynamics of each case before conducting a cross-case analysis. Specifically, the graphic organizer adapted from Yin (2003) in Figure 2 was used to initially guide this study. Yin (2003) suggests that the initial step in designing a study is theory development. As discussed earlier, the literature pointed to seven characteristics of ICC and a pilot study pointed to a preliminary theoretical framework to develop ICC (see Figure 1). I used this as my initial frame but remained open to the emergence of other characteristics identified by the participants.

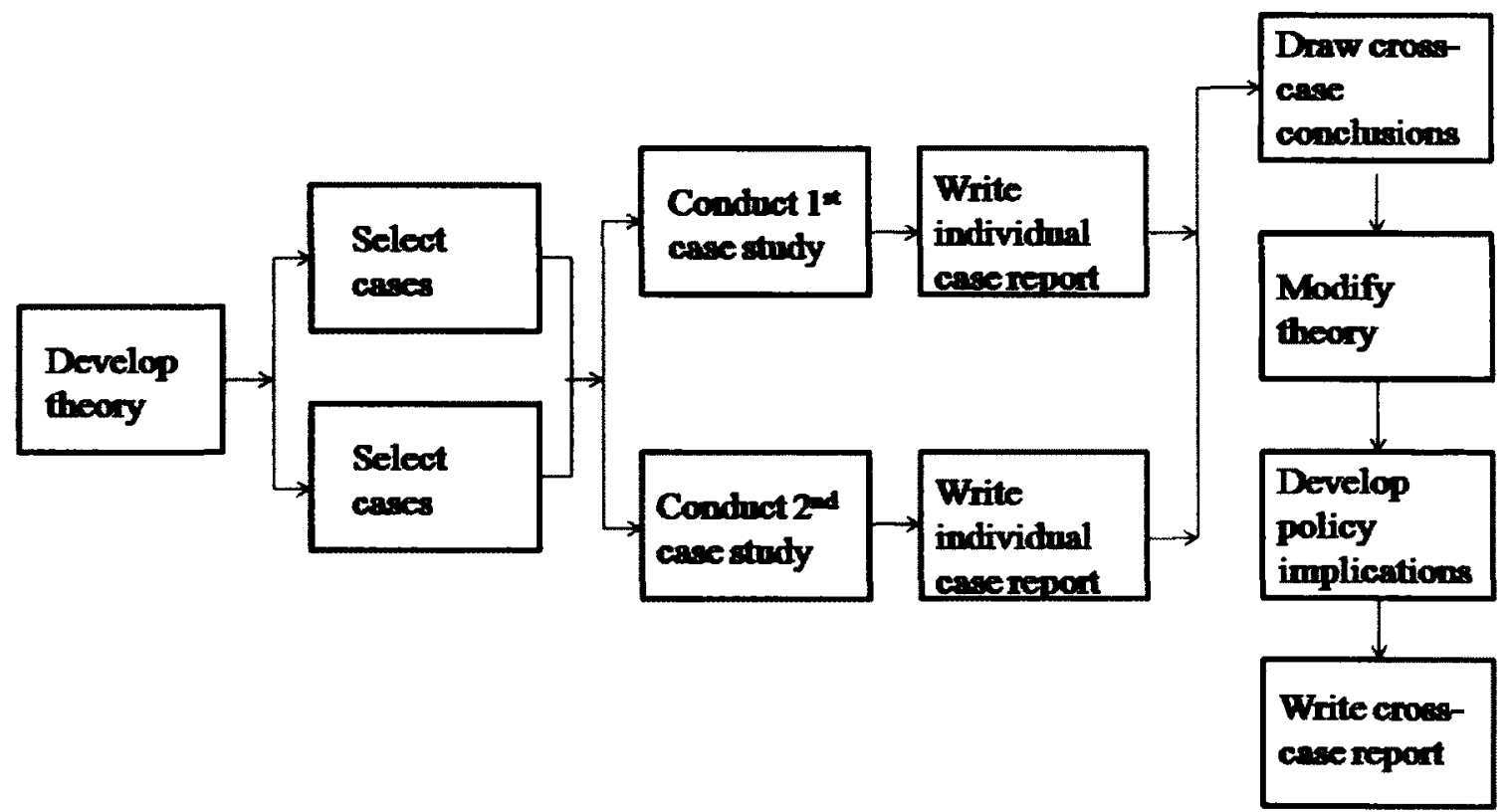

Figure 2. Case study method Adapted from Yin (2003) p. 50 
The case studies examined in this study were used to explore how graduate students who participated in a short-term study abroad course defined ICC, how study abroad courses developed ICC, and what factors facilitated or constrained ICC development. However, once an analysis of each case was completed, it made more sense to embed a cross-case analysis within each characteristic of ICC, rather than report cases individually, since there were more similarities than differences across cases. Yin (2003) posits that individual cases in a multi-case analysis serve only as the base for the study and each case does not need to be presented as a single-case study. Therefore, it was needed to present the findings in a more holistic and meaningful way by synthesizing the findings across the multiple cases rather than presenting findings from individual cases.

Findings from the comparative case study will be presented using Yin's (2003) theory-building structure, which will unravel a new and more comprehensive theoretical argument that modifies and improves upon the theory developed from the seven characteristics of ICC normally referred to in the literature that was constructed from my initial pilot study (Corbitt, 1998; Kelly \& Meyers, 1995; Mercedes \&Vaughn, 2007; Sheridan, 2005; Williams, 2005). The multi-layered construct developed from the findings reported in this study has major implications for international educators who are developing, planning, and assessing study abroad programs for developing ICC among graduate students.

Trustworthiness of Study

According to Guba (1981) there are four approaches to establish trustworthiness and rigor in qualitative research: (a) credibility; (b) transferability; (c) dependability; and (d) confirmability. Several strategies were employed to enhance the trustworthiness of 
this study. First, triangulation of multiple data sources (archived records, document analysis, and semi-structured interviews) was used to ensure confirmability, dependability, and credibility. Triangulation of data sources protects against researcher bias and is assessed against one another to cross-check data.

Second, a case study database was used for data collection and data analysis in the pilot study and final comparative case study to ensure transferability and dependability. The database was used to organize characteristics of ICC that were congruent and connected to the literature and pilot study. In addition, the case study database exemplifies stability and consistency in the process of inquiry (Riege, 2003; Yin, 2003).

Finally, the pilot study conducted in summer 2011 established dependability in the research design phase by testing the types of questions and data sources to use in this final comparative case study. As a result of the pilot study, a semi-structured interview protocol was used for all participants to establish credibility. According to Miles \& Huberman (1994), credibility is enhanced during the interview process by asking participants the same set of questions and using a model in the data analysis phase to explain theory building. In addition, credibility was also accomplished by using direct quotes from the transcriptions to authenticate the findings (Merriam, 2009).

\section{Limitations}

First, as a former graduate assistant in the PCU study abroad office, I am aware that I enter the study with my own passion for international education and am closely connected to many of the participants. Thus, I can see that my own biases could potentially alter my judgment when I am coding archival records, personal documents, and interviews because there is a natural inclination on my part to treat PCU favorably. In 
order to minimize the effect of any biases during the data analysis process, I created a systematic data coding procedure and sought out feedback on the coding scheme from an outside coder. Second, the traditional notion of generalizability is usually tied to large sample sizes and statistical procedures (Donmoyer, 1990). A major limitation of the study is that I am only getting data from two institutions and the study abroad participants were not randomly selected, which controls for selection bias. Therefore, I cannot generalize the results to all graduate students who participated in these short-term study abroad experiences. However, there were systematic techniques used in this comparative case study, such as conducting a pilot study and using a case study database in data collection and data analysis to suggest that there is opportunity to investigate the transferability of concepts developed in this study to other sites (Patton, 2002).

\section{Significance}

This study will fill a significant gap in the literature by studying graduate students who participated in a short-term study abroad experience to determine whether ICC was developed, and, if so, how and for whom. The results of this study will provide important planning and assessment implications for international educators who are using study abroad programs to develop intercultural competencies among graduate students. In addition, through this work, we may better understand how to help international educators develop appropriate learning outcomes for courses and other curriculum efforts that seek to enhance intercultural competence. 


\section{CHAPTER FOUR}

\section{Findings}

As discussed in chapter three, a qualitative comparative case study method was used for this research to explore how doctoral students at two institutions who are enrolled in a leadership studies program define intercultural competence (ICC) as a result of a short-term study abroad experience. Although leadership studies programs aspire to “developing socially responsible global learners and leaders" (SOLES, 2011d, paragraph one) and claim "to develop and enhance competencies in order to equip servant leaders for the twenty-first century" (GCGSL, 2011b, paragraph one), we still do not know what characteristics of ICC are needed to prepare global leaders. As organizations increasingly rely on higher education institutions to prepare individuals to be interculturally competent for the $21^{\text {st }}$ century, it is imperative to identify what characteristics of ICC can be developed through short-term study abroad programs.

In this chapter I present qualitative data findings from archival records, interviews, and document analysis shared by the participants to understand how characteristics of ICC relate to developing global leaders. I begin by discussing how participants defined ICC using seven characteristics. In exposing the definitions and characteristics of ICC they reported, we can begin to understand how graduate students interconnect seven characteristics in their developmental process of ICC. Next, I identify additional key factors that were found to contribute to the existing Seven Characteristics of ICC. I conclude the analysis of ICC development with a revised multi-layered theoretical model for ICC. Findings will expose the similarities and differences experienced by the participants both within each program as well as across the two 
university programs, and identify factors that facilitated and constrained their development of intercultural competency.

How Participants Confirmed the Seven Characteristics of ICC

Despite Boyatzis (1982) and Stearns (2009) recommendation for scholars to use a widely accepted definition of ICC to achieve meaningful outcome assessment, scholars continue to use varying definitions and characteristics to define ICC (Bennett and Bennett, 2004; Corbitt, 1998; Deardorff, 2004, 2006; Kelly \& Meyers, 1995; Mercedes \& Vaughn, 2007; Olson \& Kroeger, 2001; Sheridan, 2005; Williams, 2005). My literature review and findings from my pilot study suggest that the seven characteristics (ability, attitude, awareness, behaviors, knowledge, skills, and values) identified by previous research (Ang \& Van Dyne, 2008; Bennett and Bennett, 2004; Bhawuk \& Brislin, 1992; Corbitt, 1998; Cushner \& Brislin, 1996; D’Dandrea, Daniels \& Heck, 1991; DerKarabetian \& Metzer, 1992; Hammer \& Bennett, 1998; Karim, 2003; Kelly \& Meyers, 1995; Kluckhohn \& Strodtbeck, 1961; Kolb, 1999; Mercedes \& Vaughn, 2007; Olson \& Kroeger, 2001; Reddin, 1994; Roizner, 1996; Sheridan, 2005; Tucker, 1999; Ward \& Kennedy, 1999; Williams, 2005) is an appropriate lexicon to define and assess the development of ICC in this study.

The seven characteristics of ICC exposed by previous research were used to help understand participants' ICC development in this study. Research tells us that there is compelling evidence that undergraduate students who study abroad identified a change in at least one of the seven characteristics (ability, attitude, awareness, behavior, knowledge, skills, and values) of ICC (Chieffo \& Grifths, 2004; Deardorff, 2006). As discussed in Chapter 3, findings from my pilot study conducted in Summer 2011 supported the use of 
all seven characteristics to assess the development of ICC. My data analysis from this study was helpful in pushing our understanding beyond previous discussions in the literature on ICC development. It revealed that ICC was an evolving developmental process, as depicted in Figure 1, for the participants in the pilot study where the presence of some characteristics stimulated the acquisition of others. There were limitations, however, in the pilot study. Data analysis was limited, given that I only examined pre and post reflection papers from nine graduate students in one Master's level class.

This study used multiple data sources (archival records, document analysis, and interviews) to explore ICC development among doctoral students who participated in various programs. Data was examined for alternative, conflicting, or expanding characteristics of ICC. While participants identified all seven characteristics as important and necessary for ICC development, they expanded upon our understanding of ICC development because they also gave examples from their life experiences and short-term study abroad experience to demonstrate how the seven characteristics added value to their understanding of ICC. I discuss each of the seven characteristics of ICC below.

Values. Participants from PBU and PCU identified the importance of values in the development of ICC. For them, ICC meant constantly trying to understand the cultural values they were raised with and the value they placed on others in the world based on their personal experiences with their own culture and that of other cultures. In addition, when participants were asked how they defined ICC, they defined ICC as a set of values that were complex and constantly changing. Mark, a participant from PCU said, "ICC is hard to define, it is vague. Your definition and my definition could be very different." When asked to elaborate on his definition of ICC, he stated that it was complex because 
his definition of ICC is made up of his values growing up in a different culture, since his mother was from Thailand, and from what he had experienced in his life traveling across the world through the military. According to Mark, "no two people-no two cultures think the same." Mark identified character and integrity as important values that he held prior to studying abroad, and solidarity as a core value added to his life today, as a result of studying abroad to Mondragón.

Participants from PBU echoed the same thoughts about how values related to ICC. One student from PCU stated that "values from early childhood shape who you are," and added that study abroad experiences can open your mind to new cultural values. Jordan, a student from PBU, believed that the definition of ICC is built around values, and believed that when you enter a new culture, you enter their world and you need to learn the values of the other culture. Actually developing ICC, according to this student, is when you are accepting and respecting of the new cultural values.

Elizabeth referred to the connection between values and ICC, as well. She explained that the people in her life have shaped and developed her core values, and studying abroad has helped expose her to other cultural values. Having a career over family was instilled in her at a young age, and she really appreciated seeing how important family was to the British culture when she participated in the short-term study abroad to Oxford, England.

Attitudes. All participants identified attitude as an important characteristic that is essential to the development of ICC. Specifically, development of ICC could not occur unless participants had an open-mind when engaging with another culture. Attitude was described by the participants as the ability to have an open-mind when engaging with 
another culture. Hope, Mary, and Jordan, two students from PCU and one from PBU, shared that one "needs to be more open" and "have an open mind."

Participants from PCU were able to give more examples of a change in their attitude as a result of studying abroad than participants from PBU because they were exposed to more cultural differences while in Mondragón, Guatemala, Canada, and Qatar than in Oxford, England.

Some students explained attitude in terms of ICC as a shift from their original way of thinking. Hope broadly defined ICC as "suspending attitudes when interacting or engaging with another culture." Whereas Abraham was more specific and said, "an example of a shift in attitude is having an open mind to different types of foods and personalities." In other words, if you do not have an open mind towards trying new foods, you may be limiting your cultural experience. Elijah, who reflected on his trip to England concurs, "If you are a picky eater, you are going to be on the periphery of what you are learning. It's [food] part of who they are. You have got to learn to respect it." Not only did participants reflect on having an open mind to food, but also the importance of having an attitude that respected individual cultural differences. For example, Andrew explained that he had to have an open mind when he was collaborating with people in Qatar because "his way of working in groups in the U.S. was very different than the way people in Qatar worked in groups." Specifically, Andrew was referring to the distinct gender roles in the Middle East. Whether participants entered their study abroad experience with an open mind or had to shift their attitude towards certain food or cultural differences, attitude was shown to be an important characteristic to ICC. 
Awareness. Awareness of your own culture and awareness of other cultures was found to be an important characteristic of ICC among six participants. Elijah, a seasoned traveler from PBU, thinks that, “most fish don't know that they are wet until they've been yanked out of the water." Explained differently, sometimes people think they are interculturally competent, but do not realize how much they really do not know about their own culture and other cultures until they step away from their current environment. He continues and clarifies that ICC needs to begin with an awareness of your own culture:

Your culture is so deeply embedded in who you are and what you do. You have absolutely no cognizance of it at all because it's so deeply embedded in you. Until you get away from it and go get bathed and immersed in another culture with all of their cultural cues... and learn to adapt to it or at least be aware of what your culture clash is going to be when you start interacting with people. Until you do that, I don't see how you can claim to be interculturally competent. You've got to have an increased awareness of your own culture. (Elijah)

As Elijah points out, not only do you need to have an awareness of other cultures, but you need to have time to reflect on the similarities and differences that exist between your culture and other cultures. The time spent during the study abroad program was found to facilitate awareness in part because participants were able to step out of their current environment, to experience and reflect.

Behaviors. Students recognized that to successfully develop ICC, it was essential that individuals develop the behaviors that would support their interactions with people from different cultures. Isabel was one of four participants from PCU that identified a change in her own behavior as she reflected on her definition of ICC. Specifically, she identified a change in her behavior during her trip to Canada. 
I think I became more patient because that week was trying-I mean after all, I am an alpha female with my lists. I realized that it wasn't worth it; after all, I'm here to learn and I'm going to let it sink in and I'm just going to go with the flow. (Isabel)

Isabel described herself as always wanting to know what was on the agenda, and quickly realized when she was abroad that not only her attitude towards the concept of time and set agendas needed to change, but also that her behavior needed to change if she wanted to learn the Cree way of thinking and doing.

Emma also emphasized the importance that behavior played in developing her ICC. She defined behavior specifically as "embracing the differences." Emma meant that people need to change their behavior to adapt to the differences that exist between cultures and although she did not think that it was difficult for her to change her behavior while studying abroad in Mondragón, she gave an example of other participants who could not change their behavior:

When [I] saw people being ungrateful or not fully embracing the opportunity, it was irritating to see because my thought was 'you are in a completely western country.' They can speak to you in a language that is fairly familiar. It wasn't like we were totally in Ghana. So, if you were having a hard time eating the food here, why are you here? (Emma)

Respondents talked about attitude and behavior as very different characteristics. You can have an open-mind (attitude), but unless you embrace the differences, and actually have a change in your actions and reactions (behavior), you are going to prevent yourself from developing ICC. Students felt that changing behavior was an essential characteristic of ICC but changing behavior required knowledge. 
Knowledge. Knowledge, in the context of ICC, was described by one student as "studying and learning the intricacies of another culture" (Francis). This was a common sentiment from the participants from PCU, but Emma and Mark added that it is more than knowing about a country's government or economic system. ICC is "knowing and understanding that there are cultural differences" (Emma). Mark described knowledge to be "academic and technical," which primarily focused on the history of the country the participants visited; whereas, "understanding" was referred to as the depth of learning as a result of the experience of being immersed in the culture and creating a space for reflection. For example, Mark reflects, knowledge, as a characteristic of ICC, is a "process within a process" and states:

Knowledge begins within the historical context. History is going to give you context and context gives you insight about another country and the culture that exists. Through different experiences, whether it is studying abroad, or collaborating globally through technology, experiences are going to increase your level of knowledge. Experiences give you the wisdom and wisdom pushes an individual to become more educated by learning more and having the willingness to train with people from other cultures and reflect. This deeper learning takes place when there is a shift from academic and technical knowledge to an understanding. (Mark)

Mark recognized that his knowledge grew from "academic and technical knowledge" to "a deeper understanding of the culture" by studying abroad and engaging with the culture. He referred to academic and technical knowledge as "the country's history, language, the arts, sociopolitical factors, child-rearing practices/family structure, and religious practices." He gained a deeper understanding of the culture by collaborating with the culture and reflecting on his experiences. 
Christopher, a participant from PBU, found historical site visits (intercultural teaching method) beneficial and thought instructors did a good job connecting the history learned from the textbooks into contexts once they arrived to England:

One is just studying globalization and studying that simple concept, just kind of seeing I guess the juxtaposition of different cultures and your culture in one place. And then the academic, the biggest academic experience that I had there that I think helped with that, was when we visited the Ashmolean Museum, and it was interesting. It showed a lot of the intercultural trade routes and they showed how everything collided east and west just throughout ancient history. I guess reading, making us think about globalization before and then actually seeing some of it mixed together was helpful. (Christopher)

Both programs structured important curriculum content and pedagogy to help students gain knowledge and understanding. Cognitive (lectures, readings, and case studies) and intercultural teaching methods (cross-cultural dialogues) were found to be most effective. For example, Isabel explained that she had no prior knowledge of Cree culture prior to the study abroad experience. She felt the readings were necessary to increase historical knowledge.

The course was a very packed full of stuff because we were there for culture camp. So it was very intense. We read a lot before and there were pre- and post-activities... we got a couple of articles just to get us acclimated and he [the instructor] assigned a dissertation and book to read because those people had studied here, they were Cree Nation women who did their dissertations here. (Isabel)

As helpful as it was to read articles and books on what to expect before the actual travel, nothing could have prepared Isabel more than what intercultural teaching methods did for her. She found that being immersed in the culture and engaging in cross-cultural dialogues was most effective for her learning. Since there was so much to take in from 
setting up teepees, eating moose, and participating in religious ceremonies and sweat lodges, she found the best way to learn was to have a space to reflect.

In other words, ICC was more than obtaining knowledge about a culture from a textbook; for the students in this study it was also deepening the "academic" knowledge through interactions during the experiences abroad.

Skills/Abilities. Although participants did not explicitly state that ICC was about gaining a "skill," students discussed the skills that must be acquired for the development of ICC. For example, when Hope was asked to define ICC, she stated "the ability to take on a different way of thinking in order to understand someone and to communicate and engage in the dialogue." Communicating and engaging in dialogue was considered a skill to Hope. Mark, Elijah, and Christopher were more specific and said that ICC is being able to speak a language.

Participants also defined ICC in terms of developing the ability to understand and recognize differences within the culture. For example, a student from PBU who studied in England defined ICC as the "ability to see the differences in other cultures" (Elizabeth). In other words, someone cannot develop ICC if they do not have the ability to see differences that exist. It should not be assumed that everyone who goes abroad will be able to recognize differences between and among cultures. As such, Elizabeth considered ability to see differences as a skill, and an important characteristic to develop ICC.

One student from PCU who had gone to Mondragón explained that he gained the ability "to understand that relationships are important, change is inevitable, and no two cultures think the same way" (Mark). Another student from PCU also believed that 
gaining ICC was related to gaining ability to be "able to recognize different peoples world views" (Benjamin). The participants argued that ability is a characteristic that is essential in the development of ICC.

The examples described above indicate that many of the participants typically used abilities and skills synonymously. As Andrew points out, "competence by definition is [having] a proficiency at something and intercultural competency is being internationally proficient." The point Andrew was making was that competency is something that you have to work at and develop. In other words, competency is a skill. Like other "soft skills," such as communication and interpersonal skills, ICC skills relate to a person's ability to be aware of other cultures, see differences between and among cultures, and recognize different worldviews. Having the ability to develop ICC through "soft skills" was found to be important by all of the participants and thus should not be omitted from the ICC theoretical model.

Transformative Learning: Interconnecting the Seven Characteristics

In developing ICC, transformative learning must occur. Respondents' comments indicated that this kind of learning occurs when an individual engages in a process that includes reflecting on their cultural values continuously, where there is an awareness and knowledge of self and others, and when there is an emotional understanding of attitudes, behaviors, and skills/abilities of self and others.

According to Jun (2010), transformative learning is integrating intellectual understanding (knowledge) with emotional understanding (affect). For example, it is combining what you are feeling with a new understanding of difference (e.g. acceptance, surprise, fear, guilt, sadness, anger, etc.). Jun considers transformative learning as "an 
essential ingredient along with deconstructing inappropriate thinking styles/patterns because intellectual learning alone does not transcend egocentric and ethnocentric attitudes, values, and beliefs that are learned through socialization from early childhood" (p. 9). In other words, values from your childhood are so engrained in who you are as a person that it is a difficult process to deconstruct previous ways of thinking. You must be pro-active in dismantling prior beliefs.

Transformative learning is complex, but according to the respondents in this study it is because attitude, awareness, behaviors, knowledge, skills/abilities, and values are interrelated and multi-layered. For example, when a participant from PCU defined ICC, she said it was "being able to transition between your culture and then going into another culture and being able to understand that there is that difference and that you are able to function fairly well in that new culture" (Emma). For Emma, if you are truly developing ICC, you have the knowledge and awareness that there is a difference between your own cultural values and the cultural values you are experiencing, and as a result, have a change in your attitudes and behaviors. Thus, it is not enough to develop one characteristic of ICC and say that you are now interculturally competent. It is the interrelatedness of characteristics that matters.

Many respondents recognized that the characteristics of ICC were interconnected and required for development. John reflected on his ICC developmental process as a result of studying abroad in England, and recognized the interrelatedness of values, skills, knowledge, awareness, attitude, and behavior:

My value system says I want to learn about other cultures to start with... if you've got preconceived notions, you may at that moment not have the skill to really learn about another culture... I went to England, so communication skills are not a big issue of course. We speak the same 
language, but if you are going to Korea-to really be able to interact with people, you might need better communications skills. Transformative learning is what makes the difference in knowledge and awareness. You're not talking about just being aware of that culture. You're talking about really being aware of differences and nuances. When you're talking about awareness, you're talking about coming to understand why these people do what they are doing. I'm also not so sure that your attitude and behaviors don't also have linkages with the others [characteristics] as well with knowledge and with ability. (John)

John's comment illustrates that ICC development cannot be discussed unless you are discussing how characteristics are interconnected. John pointed out that his transformative learning was bridging knowledge and awareness. It was not enough to be aware of another culture. For John, knowledge and understanding of differences between his own American culture and the British culture was what facilitated his learning. Upon further reflection, John realized that a shift in his attitude and behaviors also played an important role in his development of ICC.

For other participants, it was not as easy to interconnect all seven characteristics as a result of their short-term study abroad experience because participants were still in the process of developing ICC. For Elizabeth, a participant from PBU, it was easier for her to discuss how ability impacted behavior. She believes that an individual needs "to be able to align practices [behaviors] to those differences." Having the ability to recognize difference in cultures is not enough; aligning practices in a way that is cognizant of cultural differences means that there needs to be a shift in behavior. Isabel from PCU expressed a similar sentiment. ICC is not only being able to critically think through differences and understand differences, but is also about applying a change in your behavior when engaging with another culture. Although Elizabeth and Isabel did not 
exemplify how all seven characteristics interconnected, they did demonstrate how ability and impact behavior were connected.

Like Elizabeth and Isabel who were still in the process of developing ICC, there were participants who recognized that developing ICC required the acquisition of a set of values before an individual could develop and interconnect the remaining seven characteristics. For Abraham, he defined ICC as a set of values. He stated:

I would like to think that intercultural competencies are a set of values or concepts that are espoused or have been condensed down into a theory of values or competencies. That people who go and study abroad or people who are immersed in a different culture assimilate [attitude and behavior change] over time whether they know they are assimilating them or not. (Abraham)

For Abraham, an interconnection of characteristics, such as attitude and behavior, occurred when he was experiencing another culture and he believes a change in attitude and behaviors occurs when you are exposed to different cultural values (i.e. studying abroad). This was also found true for Francis who reflected on his development of interconnected characteristics as a result of his study abroad experience to England:

I would say values were set beforehand and the awareness piece took place slightly beforehand...Awareness began to happen prior to the trip but predominantly awareness happened on the trip which led to new knowledge towards the end of the trip and continued knowledge in the reflection after the trip. So, that new knowledge affects my attitudes...You know we develop our world view and our value system. So, as we increase our cognitive thinking abilities we become more aware, that awareness would be lifted in our world view and our value system. Now as we become aware of certain things, then we say, "Oh, I'm aware of this, do I like this about myself?" So maybe yes, maybe no, and then you ultimately come back and change your world view. But for me a world view or values or belief systems definitely comes first. (Francis) 
Francis was well aware of his cultural and personal values prior to the trip, but the study abroad experience facilitated his awareness of other cultural values and helped facilitate his transformational learning by connecting the remaining characteristics of ICC.

As much as awareness often led to a profound impact on participants' values, in some cases the conflict of values was so great that a value clash undermined their ICC development and influenced their behaviors, which prevented other ICC characteristics from interconnecting. For example, when some students were asked to observe a religious ceremony that challenged their beliefs, as was the case when students viewed ceremonies by the Mayans in Guatemala or Native Americans in Canada, their religious differences created some resistance. One student who went to Guatemala reflected:

I [saw students] in Guatemala, very, very Christian students, get very uncomfortable when we saw a religious ceremony going on and I actually [saw] like visually ok, they just didn't want to engage because that would be going against their faith. I would say these [values] are also what prohibits people. I think people can still be in transformative learning but some of their values can hold them back...it just doesn't allow you to completely understand another culture if you can't even allow yourself to see their [other cultures] behaviors. I do think there are certain values that can hold you back. (Hope)

Hope's example demonstrates how a conflict of values can prevent other characteristics of ICC from developing. Specifically, Hope witnessed first-hand how values prevented someone from having an open-mind, which in turn, prevented a change in behavior.

The findings from this study show that the seven characteristics of ICC are an appropriate lexicon to define ICC. The seven characteristics of ICC help us to understand how ICC can be developed. Reflecting on participants' definitions of ICC, and delving deeper into what each characteristic meant to the participants', allows us to begin to understand how learners interconnect and develop seven characteristics of ICC. While the 
original theoretical model developed as a result of the pilot study, findings from this study revised the model to reflect the interconnecting characteristics. One way in which the model was revised was to incorporate additional characteristics that respondents noted were important for ICC.

\section{Additional Factors Contributing to Existing Model}

Although participants confirmed all seven characteristics as important and necessary for ICC development, findings from this study indicate that the seven characteristics are in themselves inadequate to develop ICC through a short-term study abroad experience. Students from PBU and PCU reported that prior experiences shaped their intentions to develop ICC. In addition, moments of cognitive dissonance, engagement with another culture, and having a space for reflection prior, during, and after the course were needed to facilitate ICC development. I discuss the importance of each of these below.

Prior experiences shaped intentions to develop ICC. Participants reported that ICC development depends on the experiences students come in with prior to going abroad. ICC development cannot occur if the study abroad course is viewed by participants as a short-term vacation. Participants in this study strongly believed that it was because of their prior travel experiences that they had the intent and willingness to develop ICC.

The two case studies at PCU and PBU were selected because they were the only universities in the United States that require all doctoral students to complete an international requirement by the time they graduate. The participants chosen for this study were selected because they all fulfilled the international requirement by completing 
a short-term study abroad experience. Although clearly more of a choice for the PCU students since they could have fulfilled their requirement in other ways (i.e. applied project with an international organization, international internship, systematic language study, international speaker events, or conducting a research project abroad), arguably students from both universities chose their leadership program in part because of their intention to engage in an international experience.

Participants from PCU stated that they wanted to engage in an international experience because they wanted to develop their cultural understanding and that you could not develop ICC if you did not have the intent or willingness to want to develop your ICC. For example, one PCU graduate student explained that you must have a focused exploration if you want to develop ICC:

I think anytime you are engaging in any international study or exploration it helps to have a focused exploration. I don't think that just being a tourist you can always engage in that [develop ICC]. I think that if you have had the practice or mindfulness to do your own study and self-work, which I would say not everyone is really capable of, then you can do it, but for the most part, my experience traveling and vacationing is very different than going on courses. You are reminded of the intent more frequently, so going back to the idea of ICC; ICC is definitely more present with me on a course than during vacations. (Hope)

It was because of Hope's previous travel experiences that she was able to identify the difference between a focused exploration and a vacation. Her prior experiences abroad helped facilitate her ICC development because she was more intentional on the reasons why she went abroad to Guatemala. For Hope, ICC was more present while she was abroad because her intentions were to develop ICC rather than traveling abroad as a tourist. 
Abraham, another participant from PCU, described his intent and existing knowledge as the prerequisites that helped him develop ICC. He stated:

I specifically chose to do Mondragón late in my program in leadership studies because I wanted to have the abilities, the knowledge, and the skills already. When I decided to go to Mondragón it was very intentional that I had chosen to do this at the very end of the program, and I could have done it with any study abroad course. It didn't have to be [Mondragón]. I could have gone to Canada with the First Nations course and probably had the same level of insight and transformative learning because that is sort of how I had structured it. I was going to get something out of this and try to be very insightful. (Abraham)

For Abraham, he was very intentional in deciding to study abroad later in his degree program. He was aware that he needed to learn more about different cultures, including Mondragón, if he wanted to experience a shift in his attitude and behaviors while abroad. To Abraham, he believed that he had the skills to communicate and engage with the culture because he entered the culture with existing knowledge about the culture, including an understanding of their values.

Although students from PBU did not get to pick where they wanted to study abroad for their last summer institute, participants stated that their intention going into the course was "to immerse in the culture" (Elizabeth) and to "get as much as [they] could out of this experience" (Jordan). Even though Oxford, England would not have been the first choice to study abroad for many of the participants, the common sentiment was that their intentions were to learn more about another part of the world and use their time in England as a cultural experience rather than a vacation. Elijah, who previously lived overseas, was one participant from PBU that would have liked to study abroad in a different country: 
Personally, I would have liked to have seen something a little more relevant to today's business and today's political structure. You know if we had gone somewhere like India or China or you know Turkey or somewhere like that, I think it would have been a little more relevant to what's going on today politically, but it was a good choice. (Elijah)

However, not all participants for PBU would have preferred a different location. For Joe, who had only traveled to Mexico to work in an orphanage prior to traveling to England and had not left the state of Texas until he "was probably twenty-one years old," felt the study abroad course was a good introduction and did not prefer a different location. Even for someone like Francis, who had travel experience to places like Guatemala, Hong Kong, and Mexico, thought England was relevant to the course topic on global leadership because "they were learning in the center of modern education" (Francis).

Students from PBU and PCU overwhelming reported that ICC development depends on the experiences students come in with prior to going abroad. Prior travel experiences were thought to shape participants intentions and willingness to want to study in another country. The lessons here are clear. International educators must be aware of the experiences each participant comes in with prior to developing, planning, and assessing ICC through short-term study abroad programs.

Reflection. Reflecting on your personal values and values of others prior, during, and after the study abroad course were found to facilitate ICC development. Values, as a characteristic of ICC, means constantly reflecting and trying to understand cultural values that you share between yourself and others. According to McCrea (2010), "Values become linked to social identities because we internalize the values of social groups to which we belong. Our social identities are also based on our ascribed social characteristics, such as sex, ethnicity, and nationality" (p. 854). 
Prior to studying abroad in Guatemala, Benjamin, a student from PCU, was asked by the instructor to write a reflection paper called the "Cultural Audit." For Benjamin, "[the cultural audit] provides one with the direction to begin to think about deeply-held assumptions, values, and beliefs." As a result of the cultural audit paper required for class, Benjamin reflected and recognized that his values, and the Chinese Christian values instilled in him during his childhood, did not always align. Thus, Benjamin believed that the cultural audit helped him ask questions about himself that he would have never thought to ask before. It was through reflection that Benjamin became self-aware of his multiple identities and became aware of conflicting values that impacted his attitudes towards other cultural values.

I think as an individual that is multicultural--that I identify as AsianAmerican, have a Chinese identity, grew up in Iowa and identify as gayAmerican--I have multiple identities. I've had the privilege to experience a variety of different values and I experienced different forms of oppression within these different classes, so for me understanding of values is very important. I do experience a lot and I'm a product of different ways of thinking, but at the same time I experience racism and homophobia in the church or you know racism in the gay community, so I have that awareness to begin with. I'm more receptive to understanding different cultures and beliefs. (Benjamin)

It was through self-reflection prior to studying abroad that Benjamin became aware of how his multiple identities impacts his values and why he respects difference.

Upon return from Guatemala, Benjamin was asked to complete a post-reflection paper for the course. Benjamin stated that the "Guatemala experience was deeply impactful for me. I ended up taking an extension in that course because I needed extra time to process. This [ICC] is a very intricate puzzle and I'm still trying to understand it." The paper was difficult for him to write because he was fearful of misinterpreting the 
culture and by no means did he now identify as "an expert on Guatemala," but rather, Benjamin was finally able to write his post-reflection paper by focusing on what he still needed to learn and do rather than writing on what he now knows about the culture. For example, Benjamin wrote,

I am convinced that there is more than enough work for me to do. I can write books. I can donate my time to volunteering. I can travel and do research. I can cultivate friendships across cultural boundaries. This trip has helped me to reevaluate my own purpose in life. (Benjamin)

Benjamin's example of using the cultural audit to reflect on cultural values prior to going abroad was a unique case. Even though there were participants in this study who went abroad to Guatemala in other semesters, the instructor teaching the course in Summer 2010 was the only instructor to ask students to conduct a cultural audit as a tool for students to reflect on values of self and others. The cultural audit paper was an example of one tool used to facilitate development of ICC by asking participants to reflect on values of self and others prior to going abroad. While only one course required private journaling (Qatar in 2010), there were opportunities for participants to reflect on values during group debriefing meetings while abroad.

A participant who studied abroad to Canada described the instructor as a facilitator. The instructor for the course was able to effectively ask questions to the group to facilitate deeper reflection of what the participants valued, were feeling as a result of similar or different values, and what critical incidents were occurring during the trip (cognitive).

He was a really good facilitator. He could see that there was stuff that we struggled with or thought we understood... he was really good in bridging to become more competent in Cree culture camp... He was really good at giving us time to speak to him to, "how do you feel? Does this affect you? 
Do you like the food?" I mean its basic stuff like that. "Did you sleep well?" So we're today we are going to talk about this bigger topic, women's role in Cree culture, Cree leaders, about the Cree Nation, and decolonization. I mean, all these topics were thrown at us at once because the camp, you're in it, and there were lectures that are part of being in the camp. So, it's living in it, just like boom, you're thrown in it. (Isabel)

Isabel's example demonstrates that reflection on values during the course is crucial. It is very easy to just go through the motions of learning about a new culture, but in order for a deeper learning to occur, there needs to be a space to reflect on the impact of the experience while abroad.

In addition, all courses required a final reflection paper and proved to provide participants with a space to reflect on values. Since reflection prompts varied, (e.g. "Reflect on your experience," "Write about lessons learned during your experience and suggestions for change in personal work," and "Leadership for the future"), not all participants specifically wrote about differences in cultural values. However, the overwhelming message was that reflection was key in the development of ICC.

Respondents also voiced strong support that reflecting on values was central to the conversation of ICC. Specifically for John, he believes that the definition of ICC is built around reflecting on values because when you enter a new culture, you enter their world and learn the values of their culture. John recognized that an important piece to developing ICC was having an on-going process to reflect on values and does not only take place while you are abroad. Francis agreed:

Did it [ICC development] happen before or after the trip? I think both. The whole process of awareness and knowledge and attitude, take much longer and probably happened after the trip. The things that are insignificant like what you order at a restaurant or whatever, that all happens pretty quickly. (Francis) 
Francis' point is that there is so much to take in during a short-term study abroad course that you need to have time to reflect on the experience when you return from another country.

There should be more space for meaningful reflections after the course. It is not enough to reflect prior and during the course. Since ICC is an on-going process, there should be more purposeful moments for reflection and connection back to your home country. Reflecting on values prior, during, and after a study abroad course was found to facilitate ICC development, since values are at the core of understanding ourselves and other cultures.

Culture. Similar to values, which were found to encompass the developmental process of ICC, engagement with culture and the culture's community were found to be essential to develop ICC. It is not just going abroad and building on what you already know, but what you do while you are abroad. Elijah, from PBU, did not think you could talk about intercultural competency, unless you were experiencing interactions with other cultures. Although it may be assumed that cultural interactions are expected to occur on any study abroad course, some international courses do no arrange time for participants to engage with other cultures. In addition, students at PCU appreciated that the instructors knew that learning about cultures had to happen outside of the classroom, in the community, schools, and churches. Whether it was engaging with locals during free time, or having planned meals with recognized leaders, participants found that opportunities for cross-cultural dialogues (intercultural teaching method) facilitated their ICC development. One student from PCU said:

I appreciated the instructor who said to us, "You don't do this very often, and you're not here very often. I would rather you guys go out and 
experience Oxford than to sit in a classroom and let me talk to you about business or leadership concepts." She kind of pushed us ahead of time before we got to Oxford to do a lot of that stuff. We had this whole day of just talking about all of our course work then she was able to give us a little bit of extra time to do that. So, I think that was a very good thing for her to do in terms of increasing it [ICC development]. (Christopher)

Andrew reinforced the importance of cultural engagement. He believed that his ICC was developed because he was given the opportunity to collaborate with those in the community:

I think there is a big difference in traveling over to Europe just to have a good time versus going over and actually working and being asked to produce a product. So, that I think is a big thing. I can be fairly competent in going over and traveling and seeing the sights, but it's a whole another thing to be in a group setting with a group of people who you aren't familiar with-- in a culture you've never experienced before up until that point--and being asked to collectively produce a product that you are going to share with everyone else. (Andrew)

For Andrew, he was not experiencing the culture unless he was actually collaborating with people from Qatar. Collaborating and engaging with the culture was more than eating at a restaurant, walking the city, and people watching; for him, experiencing the culture was working as part of a team.

Abraham also agreed regarding the importance of engagement with the community. Andrew believes that transformational learning is more than understanding yourself. He suggested that transformational learning moves learning from individual learning (understanding of self) to community learning (understanding others). For him, this is the developmental process of ICC. In other words, development of ICC is truly engaging with another culture by working together (e.g. common project, problem, assignment, etc,), but also continuing that work when you return to your home country. 
Where does the communal learning and the communal transformation come in? Because it is so great if people can have individual transformational learning, and I would really hope that all of my classmates and everyone in the world and everyone in this program are truly transformed by the learning that they get in the leadership studies program or in the study abroad course. When we were thinking about the really big problems in the world, leadership-wise, and we all realize that, you know, we are becoming a more global world, and we want to all become global citizens, but what does that mean? How do we transform the learning in a community and as a society? And when I don't see change at that level, for me, it's not transformative enough. (Abraham)

Some participants found that the course design constrained ICC development since the length of the course prevented interactions with another culture. Participants found short-term study abroad courses ranging from 5 to 14 days limiting because they did not have enough time to explore outside of the structured program. A structured schedule with a set agenda prevented participants from having time to engage with the local community. Participants had hoped there would have been more time for selfexploration with the culture and community:

The schedule we had didn't give us any break at all. We ran every day from seven in the morning until eleven at night straight. There was no downtime. If we weren't touring around, we were out doing some other activity and then we had to eat with people and then we got back, and we did that for a whole week. And then, the one day they had scheduled for us to be off- it was their Sunday of the week, which meant that everything was closed. So on our day off, the only day off we had, the whole time, nothing was open and we couldn't go anywhere because nothing was open. And then because part of what we were being asked to do is go out and experience the culture, and for me, I'm not experiencing culture when I'm sitting on a bus touring around. I am talking with people, haggling for some silk scarf, learning about the culture and how to interact with people. Seeing how they interact with each other. Hearing their conversations or at least the tone of their conversations. Driving around on the bus and seeing the sights and looking at this and that and the other thing, it gives me a picture of what it is, but I can't say I'm gaining necessarily any sort of competency on it unless I'm actually out there doing it. And the one day that we actually could go and go out and actually do that on our own 
without structure, in a sense, there was nothing. We couldn't do anything. (Emma)

Participants from PBU would have liked to have more interaction with international students and other cultures in England to expose themselves to other perspectives. For example, participants complained that courses were taught by the instructors from their home institution. Here they were visiting another college in England, but did not have the opportunity to be instructed by faculty in England, or to engage with any international students (either from England or students studying abroad in England).

There were two issues that I thought were a little bit problematic with the study abroad course. The length I thought was a little short. I would like to have had a longer period of study there. The other was that the professors that taught our courses were all from PBU and I would like to have more interaction with the professors from Regent College. Because Regent College closes during the summer when we went, there were fewer students and they rent out their dorms and things, so there were some students there but not a lot. And so, the interactions with other international students was fairly, fairly limited. (John)

Emphasizing the benefit of gaining access to the host country's university professors, John thought that the best learning happened outside of the course, when they had dinner with professors from Regent College:

We had a lot interaction with the professors from Regent College, because we had our meals with them. We did things with them in the evenings and things like that. And so, it's not that we had no interaction with them. In fact, some of those informal discussions over the meals were some of the best teaching tools they had and were we're not part of the formal instruction. (John)

Therefore, short-term study abroad courses would be better served if they were arranged to provide more engagement with the culture, more engagement with the content from the 
country, and were offered an opportunity to gain a deeper international perspective.

Moreover, some participants from PBU would have liked to spend more time discussing what global leadership means from an intercultural perspective (since that was the focus of the summer institute), or would have liked to study in another country (since England was the only option). For example,

The globalization of our existence in society is irreversible. We're not going to go back. We can't go back to prior to pre-globalization. So, I think it's absolutely mandatory that everybody who is going to call themselves a leader, whether he is leading a small local church or a small local business, physically go places and be a leader in other places, he needs to be able to relate to others around the world in different aspects. I just think it's essential. Whether or not we had to go overseas to do this, to accomplish it, I'm not sure that we had to. And again, I still think that that trip was too much like our own culture to have had the greatest impact that it could have had. (Elijah)

Individuals want to understand and engage with another culture. Respondents in general indicated that ICC development cannot happen unless you are learning about other cultures. The way to learn about other cultures is to truly engage by collaborating together.

Cognitive Dissonance. Study abroad experiences often prompt cognitive dissonance. According to Festinger (1957), cognitive dissonance is the discomfort felt between what you already know, believe, or feel when faced with new information, interpretation, or environment. In other words, cognitive dissonance is when there is a discrepancy between values and behaviors, and there is a feeling that something must change (e.g. attitude, behaviors) in order to eliminate or reduce dissonance. Students such as Benjamin believe you need to experience cognitive dissonance while abroad before transformative learning can occur. Reflecting on his experience to Guatemala, he stated: 
It's not just I want to learn, there is something that provokes learning and I think the transformation process, in adults, that if there is no problem to solve, people are not going to transform themselves, so it's one of those things, the chicken or the egg kinda thing, is it the want to change or is there something else that drives the process? (Benjamin)

For Benjamin, his first moment of cognitive dissonance while abroad was when he stepped out of the plane in Guatemala:

The thing that provoked me at the start of the trip was at the airport. I was very, very nervous because I was in this country and you know as an outsider, as an American I know what I hear about Guatemala and other Latin America countries--that there is violence, there is drugs, you are going to get kidnapped-- and my family discouraged me from going there and my instructor promised to pick me up from the airport and I was still so freaked out about how to get around when I got there. I would say that's my cognitive dissonance... After you step out of the airport and even when you are landing at the airport, it is a surreal experience because there is a broken plane. The buildings, the people are not the same, technology is not the same, so my senses are overwhelmed with these different kinds of stimuli and I'm wondering why is the world like this? Why is it different from the world I grew up in? What in history happened that led to the reality that I'm experiencing right now? (Benjamin)

As Benjamin began questioning why there was a discrepancy between the way he lived in the United States and the way people lived in Guatemala, he began reassessing his relationship with the country and its people. Although Benjamin was aware that differences existed, he could not help but feel guilt when he witnessed cultural difference first-hand. Actually seeing how people lived and having a moment of discomfort when his values did not align with what he saw in Guatemala helped Benjamin develop ICC.

In addition, for some participants, "cognitive dissonance" caused a shift in attitudes and behaviors. For example, Andrew's first moment of discomfort was when he stepped off the plane, but he also questioned his attitudes and behaviors when he engaged with the culture for the first-time: 
I remember looking out the window and landing and thinking to myself, "Wow, this is not any place I've ever been. Then getting off and there are signs in English but there are lots of things that are not in English. Symbols that you've never seen before, then thinking, "Okay, now what do I do?" And probably the first time we were at the Souq [open-air marketplace] because that was really the first time where we were in a public setting. Where we are shopping and eating and have menus--you don't know what you're doing and you want to make sure you ordered the right foods and you get chicken and not camel. I think all it took was the first time and understanding and interacting with them because you're not sure as how you're supposed to act or react to things. (Andrew)

Even though Andrew's example of cognitive dissonance was given for a nonwestern culture (Qatar), this is not to say that students have to visit a non-western culture to feel cognitive dissonance, because everyone enters a study abroad course with different value systems and travel and cultural experiences. For someone who has never traveled, a cognitive dissonance could have happened if they went to Mondragón, Canada or England, places with presumably less cultural difference than what one is likely to encounter in countries such as Qatar. A participant reflects on a student who went to Mondragón with her and questioned their ability to develop ICC:

I recall one guy being on our trip and it was his first time to Europe, and he was struggling a little bit. I was thinking, if you're struggling with being in the Basque region of a western European country, I'd hate to see you in a less-developed country. So, that told me that not everybody was at the place where I was, and I think probably more instruction might have been beneficial to those people that were expecting an experience similar to one you would find here in the United States, and it was, but still a different country. In my opinion, there weren't that many stark differences. (Emma)

When participants from PBU were asked if they had any moments of discomfort in attitudes and behaviors, they responded that they did not necessarily feel like they were in another country because they could not think of examples where they were out of their comfort zone. For example, one participant responded, "I can't think of anything where I 
just said, 'Oh my gosh, I'm not in Kansas anymore"” (Francis). However, there were some participants that had minimal travel experience outside of the United States and stated that they probably had different levels of discomfort than their classmates because they had different levels of ICC prior to studying abroad.

Findings from this comparative case study affirmed the seven ICC characteristics identified in the pilot study, and expanded upon ability, attitude, awareness, behaviors, knowledge, skills, and values (Corbitt, 1998; Kelly \& Meyers, 1995; Mercedes \& Vaughn, 2007; Sheridan, 2005; Williams, 2005) to add prior experiences, reflection, culture, and cognitive dissonance to develop ICC. Throughout the study, the original theoretical model created in Figure 1 was revisited and revised as each characteristic of ICC was discussed by the participants.

Revised Theoretical Model of ICC

When conducting this study, I used the seven characteristics of ICC found in the literature to help question participants about their ICC development (Corbitt, 1998; Kelly \& Meyers, 1995; Mercedes \&Vaughn, 2007; Sheridan, 2005; Williams, 2005). Since there was compelling evidence in the literature to support that undergraduate students who studied abroad had identified a change in at least one of the seven characteristics of ICC (ability, attitude, awareness, behavior, knowledge, skills, and values) (Chieffo \& Griffths, 2004; Deardorff, 2006), it was important to explore whether or not change along the same set of characteristics would occur among graduate students, and influence their ICC development. Findings from my pilot study conducted in Summer 2011 revealed that ICC is an evolving developmental process, as depicted in Figure 1, and actually helped me to construct a developmental model of ICC in a more complex and helpful way. 
Several scholars have proposed conceptual models that only identify one of the seven characteristics of ICC (Corbitt, 1998; Hammer \& Bennett, 1998; Kelly \& Meyers, 1995, Williams, 2005). To date, there is not one framework that identifies all seven characteristics (ability, attitude, awareness, behaviors, knowledge, skills, and values) or their interrelatedness for developing ICC. Based on findings from this study, all seven characteristics should be considered, because all seven characteristics of ICC were present and moreover, they were viewed by participants as interconnected and therefore must be reflected as such in the model.

In addition, findings from this study indicate that the seven characteristics are in themselves inadequate to define ICC. Several important new factors emerged from this study. Students reported that prior experiences shaped their intentions to develop ICC, engagement with cultures, moments of cognitive dissonance and reflection prior, during, and after the study abroad course were key factors to developing ICC.

The Seven Characteristics of ICC seen in Figure 1 were revised and modified throughout the study during data collection and data analysis to develop a theoretical model for understanding the Development of ICC in a more comprehensive way (see Figure 3). The models created in this study are not intended to over simplify a complex phenomenon. Rather, the models are intended to visually demonstrate that the characteristics are multi-layered and interconnected. A comparison of the models will be discussed in Chapter 5. 


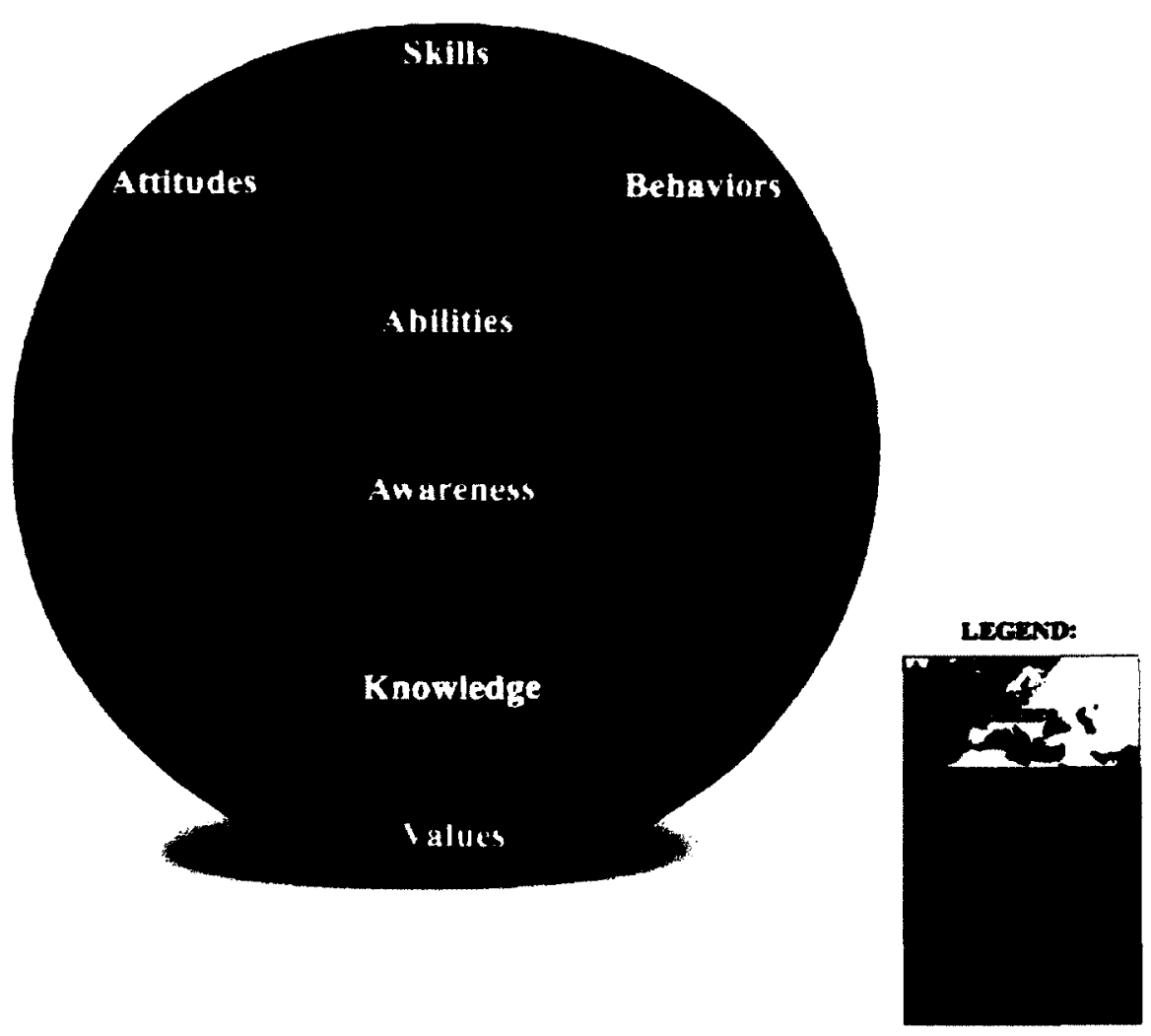

Figure 3. Development of ICC

As a result of the comparative case study, the 14 participants in this study gave evidence that an individual's values shaped from early childhood (e.g. family, schools, religion, and culture) impacted development of ICC. As in the pilot study, values were found to embody the entire developmental process of ICC, because values make up who a person is. Self-assessment of values and how they impact others was found to be an ongoing process. However, culture was missing from the original model in Figure 1 (see Figure 4 for a comparison of models). We learned from the participants in this study that an individual's values make up a person's culture, and ICC cannot be developed unless you are engaging with another culture and understanding personal values from other cultures (self and others). Therefore, the globe symbolizes that culture and values are the 
foundation of the developmental process and all seven characteristics of ICC coexist with culture and values. This is visually represented by being able to see the globe through all four layers of the developmental process. It is important to note that although values are written at the bottom of the globe, values are interconnected with culture (see legend on Figure 3), which makes up the entire globe.
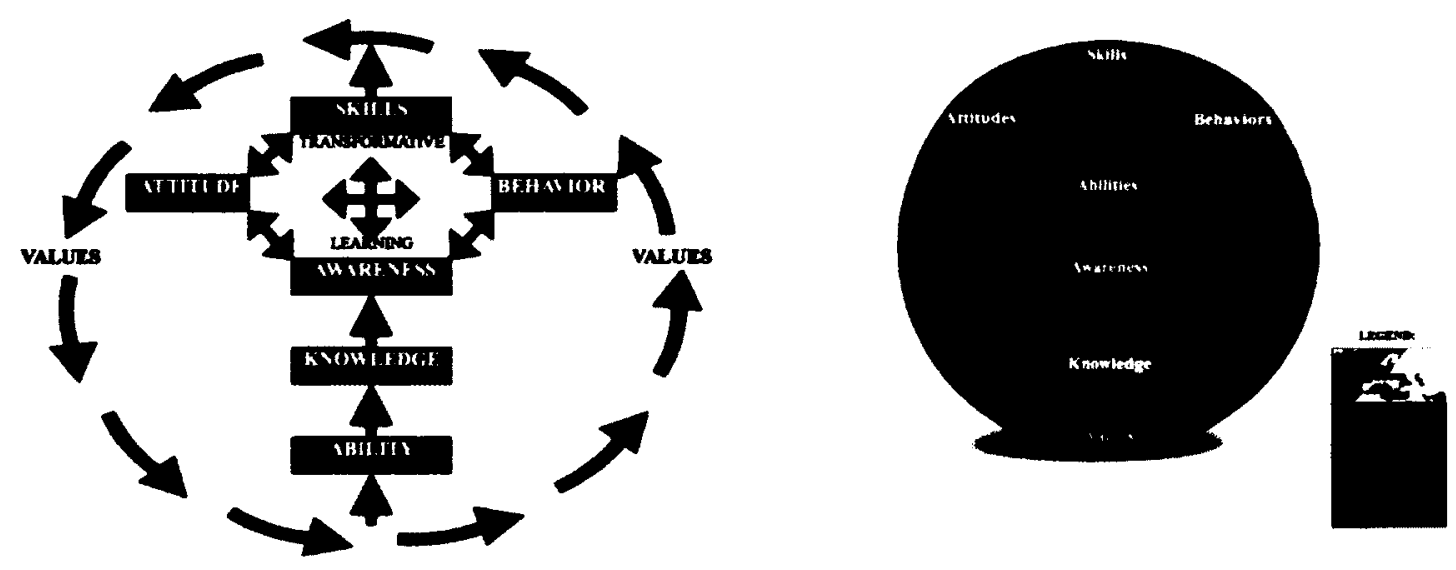

Figure 4. Comparison of models

The original Seven Characteristics of ICC model depicted in Figure 1 was also revised to symbolize that layers exist between knowledge, awareness, abilities, attitudes, behaviors, skills, values, and culture, opposed to the arrows, which implied that participants advanced through the seven characteristics in stages. Knowledge can be broken down into three layers: history, experience, and reflection. Historical knowledge (identified as a light blue circle above values and culture in Figure 3) is when participants learn cultural practices and worldviews. Typically, historical knowledge about a culture is obtained through cognitive teaching methods (readings, films, lectures, conference presentations), active teaching methods (role play, simulation), and intercultural teaching methods (immersion). 
The second layer within knowledge is experience. Experience (blue layer identified above knowledge in Figure 3) is immersing oneself with another culture, and one is engaging and interacting with another culture. Values and culture continue to embody the development process, as well as historical knowledge about another culture. In the experience layer, individuals continue to learn about self and others, and as a result may experience cognitive dissonance. Cognitive dissonance triggers awareness and can cause a shift in attitude and behavior. A shift in attitude and/or behavior can occur while they are experiencing the culture, or cause a shift after they have reflected on the experience, which is why attitudes and behaviors are written between experience and reflection.

The third layer of knowledge is reflection. Reflection is the final layer of knowledge added to the model. Reflection can take place at any time and was found to be instrumental in assisting ICC development prior to going abroad, during, and when they returned. In addition, it was found that transformative learning took place in the third layer, when participants were constantly reflecting back on personal and cultural values, and what they learned from historical knowledge and experience.

Transformative learning is when participants have an awareness that causes a shift in attitude, behavior, and skills/abilities (e.g. interpersonal and intrapersonal communication styles). When there is an awareness of how their own values impact others, awareness can cause a shift in attitude towards cultural differences and in their behavior when interacting with people from another culture. However, this is not always easy. It often takes a set of learned skills and abilities to have a shift in attitudes and behaviors. For example, it takes a skill to be able to communicate with someone from 
another culture and it takes a skill to take on a new way of thinking. As Jun (2010) explained, "The emotional component of transformative learning means that it cannot be hurried. It takes time to process complex emotions, desires, wants, and should" (p. 11). In other words, it takes time to develop all characteristics of ICC and transformative learning does not always happen immediately.

The revised theoretical model for developing ICC demonstrates how additional key factors (i.e. culture, cognitive dissonance, and reflection) significantly alter our understanding of the ICC phenomenon. Scholars should no longer look at characteristics of ICC individually since the findings indicate that all seven characteristics and additional key factors are multi-layered and interconnected. The theoretical model created as a result of this study will help international educators who are developing, planning, and assessing study abroad programs for our future global leaders. In addition, the new theoretical model will help individuals understand their developmental process and help bring an awareness of the characteristics needed to develop ICC. 


\section{CHAPTER FIVE}

\section{Discussion and Conclusions}

Chapter five presents a summary of this research study that includes a statement of the problem, purpose statement and research questions, a review of the methodology, and a summary of the findings. Additionally, implications for practice are suggested as a result of the findings. I will conclude by proposing recommendations for future research.

\section{Statement of the Problem}

Several studies have examined the impact of study abroad programs at the undergraduate level, with a specific focus on long-term study abroad programs. While multiple studies discuss the advantages of long-term study abroad programs such as increased levels of intercultural communication, cross-cultural adaptability, cross-cultural sensitivity (Williams, 2005), and foreign language acquisition (Dwyer, 2004), there is limited research available on the impact of short-term study abroad programs for graduate students.

To date, studies have found undergraduate students who participated in short-term study abroad programs to be more confident in their levels of intercultural awareness and functional knowledge (Chieffo \& Griffiths, 2004), and to have a greater appreciation for

diverse cultures, and enhanced awareness pertaining to their own culture (Anderson et al., 2006). Although short-term study abroad programs are growing for graduate students, there is a lack of scholarly research exploring whether or not intercultural competencies can effectively be developed through these programs. 
Purpose of the Study

The purpose of this study was to investigate the experiences of 14 graduate students who participated in a short-term study abroad program at two different universities, and to assess their ICC development. The seven characteristics of ICC generated from the existing research on the development of ICC among undergraduate students helped to frame my investigation of the experiences of graduate students. The seven characteristics of ICC found in the literature and described previously are: ability, awareness, attitude, knowledge, skills, behavior, and values (Corbitt, 1998; Kelly \& Meyers, 1995; Mercedes \&Vaughn, 2007; Sheridan, 2005; Williams, 2005).

The results of this study are important for international educators who are developing, planning, and assessing study abroad programs for graduate students. In addition, students interested in developing their ICC will gain a better understanding of the factors that facilitate and challenge their efforts.

The following research questions guided the study:

1. How do graduate students at two different institutions who are enrolled in a leadership studies program define their ICC as a result of a short-term study abroad course experience?

2. What factors facilitated or constrained students to develop the seven characteristics of ICC?

3. How do we account for the similarities and differences experienced by the participants both within and across the two university programs?

Review of the Methodology

A qualitative, comparative case study method was used for this study. The Department of Leadership Studies at Private Catholic University (PCU) and the Graduate School of Leadership at Private Baptist University (PBU) proved to be unique case 
studies since they are the only leadership studies programs in the United States of America to require all doctoral students to complete an international experience. They provided excellent opportunities to examine the extent to which short-term study abroad programs develop graduate students' seven characteristics of ICC. Data was drawn from archival records, document analysis, and interviews. Once an analysis of each case was completed, a cross-case analysis was conducted to modify and improve upon the theory developed from the seven characteristics of ICC (Corbitt, 1998; Kelly \& Meyers, 1995; Mercedes \&Vaughn, 2007; Sheridan, 2005; Williams, 2005) constructed from my initial pilot study.

Summary of the Findings

Research question one. How do graduate students at two different institutions who are enrolled in a leadership studies program define their ICC as a result of a shortterm study abroad course experience? Although data was examined for alternative, conflicting, or expanding characteristics of ICC, participants identified all seven characteristics as important and necessary for ICC development. Reflecting on participants' definitions of ICC and delving deeper into what each characteristic meant to the participants allows us to begin to understand how graduate students interconnect and develop the seven characteristics of ICC.

In addition to the seven characteristics of ICC, findings from this study revealed that other factors were identified as crucial to the Development of ICC. Specifically, higher education program directors would be well advised to take the competencies of the participants into account, given that respondents noted how their prior experiences shaped their intentions to develop ICC. Another key factor that emerged from the data 
was that students required moments of cognitive dissonance for ICC development, and also benefited from having a space for reflection prior, during, and after the course.

Research question two. What factors facilitated or constrained students to develop the seven characteristics of ICC? Participants identified the same additional key factors used to define ICC (moments of cognitive dissonance, engagement with the culture, and having a space for reflection prior, during, and after the course) as important factors to facilitate ICC development. In addition, this study showed that when students have limited interactions with the culture of the host country, their ICC development was constrained. Moreover, students indicated that study abroad programs should focus on cognitive and intercultural teaching methods to facilitate ICC development, which includes, but is not limited to, gaining multiple perspectives and interacting with the people in the community and culture.

Research question three. How do we account for the similarities and differences experienced by the participants both within and across the two university programs? Findings from the two university programs coalesced even when the short-term study abroad programs were arguable different experiences. Originally, cases from the two institutions were going to be presented individually to account for similarities and differences both within and across the two university programs; however, once an analysis of each case was completed, it made more sense to embed a cross-case analysis for each characteristic of ICC discussed, since there were more similarities than differences across cases. As a result, the findings were presented in a more holistic and meaningful way by synthesizing the findings across the multiple cases, which resulted in a revised theoretical model for developing ICC. 


\section{Comparison of Models}

The original theoretical model created in the pilot study was revised and modified to develop a multi-layered theoretical model for understanding the Development of ICC in a more comprehensive way (see Figure 3). The models created in this study are not intended to over simplify a complex phenomenon. Rather, the models are intended to visually demonstrate that the characteristics are multi-layered and interconnected. Table 5 is a comparison of the theoretical models developed as a result of the pilot and comparative case studies. Characteristics of ICC defined in the pilot study are located on the left hand side of the table, while key factors added to the model as a result of the final case study are added to the right column of the table. In addition, each characteristic listed on the left column includes the relationship to other characteristics for both models. Key differences between models are seen in italics.

The Development of ICC model was revised to symbolize that culture and values are the foundation of the developmental process, and to show that layers of knowledge (history, experience, and reflection) interconnect with values, culture, awareness, attitudes, behaviors, and skills/abilities. 
Table 5: Comparison of theoretical models

\begin{tabular}{|c|c|c|}
\hline \multicolumn{2}{|c|}{$\begin{array}{l}\text { SEVEN CHARACTERISTICS OF ICC } \\
\text { (FiguRE 1) }\end{array}$} & $\begin{array}{l}\text { ADDTIONS TO DEVELOPMENT OF ICC } \\
\text { (FIGURE 3) }\end{array}$ \\
\hline Values & $\begin{array}{l}\text { Reflecting and reassessing values } \\
\text { learned from early childhood and } \\
\text { valuing relationships with people from } \\
\text { another culture. }\end{array}$ & $\begin{array}{l}\text { Reflecting on personal experiences prior, } \\
\text { during and after study abroad course. }\end{array}$ \\
\hline $\begin{array}{l}\text { Relationship to } \\
\text { other } \\
\text { characteristics }\end{array}$ & $\begin{array}{l}\text { Values embody the entire developmental } \\
\text { process of ICC (ability, knowledge, } \\
\text { awareness, attitude, behaviors, and } \\
\text { skills). }\end{array}$ & $\begin{array}{l}\text { The foundation of a multi-layered } \\
\text { developmental process of ICC. Coexists with } \\
\text { culture, historical knowledge, } \\
\text { experience/cognitive dissonance, awareness } \\
\text { and reflection, and transformative learning!. }\end{array}$ \\
\hline Ability & $\begin{array}{l}\text { The intent and readiness to immerse in } \\
\text { another culture. }\end{array}$ & $\begin{array}{l}\text { Referred to as a skill to understand, recognize } \\
\text { and reflect on cultural differences. }\end{array}$ \\
\hline $\begin{array}{l}\text { Relationship to } \\
\text { other } \\
\text { characteristics }\end{array}$ & $\begin{array}{l}\text { Ability is the entry point to gaining new } \\
\text { knowledge. }\end{array}$ & $\begin{array}{l}\text { Ability viewed as multilayered with culture and } \\
\text { values, three layers of knowledge (history, } \\
\text { experience/cognitive dissonance, reflection) } \\
\text { and interconnected to transformative learning'. }\end{array}$ \\
\hline Knowledge & $\begin{array}{l}\text { Learning about different cultural } \\
\text { practices and worldviews. }\end{array}$ & $\begin{array}{l}\text { More complex understanding of knowledge. } \\
\text { Historical context (academic and technical } \\
\text { knowledge), experience/cognitive dissonance, } \\
\text { and reflection. }\end{array}$ \\
\hline $\begin{array}{l}\text { Relationship to } \\
\text { other } \\
\text { characteristics }\end{array}$ & $\begin{array}{l}\text { Development of knowledge is linear and } \\
\text { triggered by values and ability. }\end{array}$ & $\begin{array}{l}\text { Viewed as multi-layered consisting of } \\
\text { historical knowledge, experience/cognitive } \\
\text { dissonance and awareness, reflection and } \\
\text { interconnected to transformative learning }\end{array}$ \\
\hline Awareness & $\begin{array}{l}\text { How own cultural worldview impacts } \\
\text { the culture they are exploring and } \\
\text { examining similarities and differences } \\
\text { that may exist between cultures. }\end{array}$ & $\begin{array}{l}\text { Historical knowledge not enough to develop } \\
\text { awareness. Development requires experiencing } \\
\text { cultural worldviews and experiencing a } \\
\text { cognitive dissonance. }\end{array}$ \\
\hline $\begin{array}{l}\text { Relationship to } \\
\text { other } \\
\text { characteristics }\end{array}$ & $\begin{array}{l}\text { Awareness developed as a result of } \\
\text { knowledge, and ability. Awareness } \\
\text { considered entry point to transformative } \\
\text { learning (attitude, skills and behaviors). }\end{array}$ & $\begin{array}{l}\text { Awareness layered with historical knowledge } \\
\text { and experiencing the culture and values. } \\
\text { Experience/cognitive dissonance and } \\
\text { awareness interconnected to transformative } \\
\text { learning. }\end{array}$ \\
\hline Attitude & $\begin{array}{l}\text { A shift in understanding of self and } \\
\text { cultural differences. }\end{array}$ & Developing an open-mind resulting to change. \\
\hline
\end{tabular}


Table 5 (con't)

\begin{tabular}{|c|c|c|}
\hline $\begin{array}{l}\text { Relationship to } \\
\text { other } \\
\text { characteristics }\end{array}$ & $\begin{array}{l}\text { Attitude is linked to transformative } \\
\text { learning (awareness, behavior, and } \\
\text { skills) and can be triggered by a shift in } \\
\text { awareness, behavior, and skills. }\end{array}$ & $\begin{array}{l}\text { Development as a result of reflection, } \\
\text { experience/cognitive dissonance, historical } \\
\text { knowledge and engagement with culture. } \\
\text { Layered with transformative learning'. }\end{array}$ \\
\hline Behavior & $\begin{array}{l}\text { A shift in how an individual acts as a } \\
\text { result of developing an increased level } \\
\text { awareness and knowledge. }\end{array}$ & $\begin{array}{l}\text { Embracing difference, having a change in } \\
\text { actions, reactions, and interactions with people } \\
\text { from different cultures. }\end{array}$ \\
\hline $\begin{array}{l}\text { Relationship to } \\
\text { other } \\
\text { characteristics }\end{array}$ & $\begin{array}{l}\text { Behaviors triggered by awareness, } \\
\text { Behaviors linked to transformative } \\
\text { learning (awareness, attitudes, and } \\
\text { skills). }\end{array}$ & $\begin{array}{l}\text { Development as a result of reflection, } \\
\text { experience/cognitive dissonance, historical } \\
\text { knowledge and engagement with culture. } \\
\text { Layered with transformative learning'. }\end{array}$ \\
\hline Skill & $\begin{array}{l}\text { Cross-cultural communication and } \\
\text { thinking styles. }\end{array}$ & $\begin{array}{l}\text { Ability to take on a different way of thinking in } \\
\text { order to understand, communicate and engage } \\
\text { in dialogue. }\end{array}$ \\
\hline $\begin{array}{l}\text { Relationship to } \\
\text { other } \\
\text { characteristics }\end{array}$ & $\begin{array}{l}\text { Skills triggered by awareness, attitudes } \\
\text { and behaviors. Skills linked to } \\
\text { transformative learning (awareness, } \\
\text { attitudes, and behaviors). }\end{array}$ & $\begin{array}{l}\text { Multilayered and interconnected to reflection, } \\
\text { experience/cognitive dissonance, historical } \\
\text { knowledge and transformative learning. }\end{array}$ \\
\hline & & $\begin{array}{l}\text { Culture as a characteristic of ICC is } \\
\text { engagement and interactions with culture and } \\
\text { the culture's community. } \\
\text { The foundation of a multi-layered } \\
\text { developmental process of ICC. Coexists with } \\
\text { values, historical knowledge, } \\
\text { experience/cognitive dissonance and } \\
\text { awareness, reflection, and transformative } \\
\text { learning. }\end{array}$ \\
\hline
\end{tabular}

Tote: Transformative learning (attitudes, abilities, behaviors and skills) interconnected to three layers of knowledge (Layer 1: Historical knowledge; Layer 2: Experience/Cognitive Dissonance and Awareness; Layer 3: Reflection)

\section{Implications of the Study}

Several implications for practice can be drawn from this study. First, degree

programs that claim to prepare "global leaders" should be examined more closely. How can a degree program prepare global leaders if they do not require students to engage with another culture? Considering there are only two leadership studies programs in the United States that require an international experience (and one of the programs only studies in Oxford, England), leadership studies programs should consider adopting an international requirement that requires students to engage in a non-western country with a purpose to facilitate Development of ICC. 
Second, global leadership programs that claim to prepare leaders for the $21 \mathrm{st}$ century must offer a global leadership course that focuses on the seven characteristics of ICC plus the additional key factors (i.e. prior experiences, culture, cognitive dissonance, and reflection). Although PCU required all of their doctoral students to complete an international requirement, students stated that they were never taught what ICC or global leadership meant. Moreover, students enrolled in the Ph.D. in Leadership Studies at PCU were never required to enroll in a global leadership course. Leadership studies programs need to remember that global leadership is more than just learning the history of a country (academic knowledge) from a textbook. Therefore, programs that offer a global leadership course, like PBU, should consider revising the course to facilitate Development of ICC to successfully work within and across cultural boundaries. Moreover, students should be asked to engage with non-English speaking cultures as part of the global leadership course requirement.

Third, courses on and off campus should be designed for different learners. Courses should be developed by incorporating Fowler and Blohm's (2004) cognitive, active, and intercultural teaching methods. With that said, more effort needs to be made to engage students outside of the traditional lectures and site visits. Although lectures, reading, films, cross-cultural dialogues, and immersion were found to facilitate ICC development, courses should apply additional teaching methods, such as case studies, role playing, and simulation exercises to aid different learners and facilitate Development of ICC. Table 6 summarizes the characteristics of ICC generated from this research with suggested strategies to engage and develop specific ICC characteristics, expected learning outcomes, and best time to implement strategies (i.e. pre-trip, while abroad, 
post-trip). All suggestions are a result from the lessons learned from the respondents in

this study.

Table 6. Expected learning outcomes to develop characteristics of ICC

\begin{tabular}{|c|c|c|c|}
\hline $\begin{array}{l}\text { CHARACTERISTIC } \\
\text { S OF ICC }\end{array}$ & $\begin{array}{l}\text { STRATEGY TO } \\
\text { DEVELOP ICC } \\
\text { CHARACTERISTICS }^{1}\end{array}$ & EXPECTED LEARNING OUTCOME & $\begin{array}{l}\text { TIME OF } \\
\text { IMPLEMENTATION }\end{array}$ \\
\hline \multirow[t]{2}{*}{ Prior Experiences } & \multirow[t]{2}{*}{$\begin{array}{l}\text { Self-assessment } \\
\text { (written reflection) }\end{array}$} & $\begin{array}{l}\text { To identify intentions to engage in an } \\
\text { international experience }\end{array}$ & \multirow[t]{2}{*}{ Pre-trip } \\
\hline & & $\begin{array}{l}\text { To evaluate existing knowledge about } \\
\text { culture }\end{array}$ & \\
\hline \multirow[t]{3}{*}{$\begin{array}{l}\text { Values/ } \\
\text { Culture/ } \\
\text { Reflection } \\
\text { (knowledge) }\end{array}$} & \multirow[t]{3}{*}{$\begin{array}{l}\text { Self-assessment } \\
\text { (written reflection) }\end{array}$} & $\begin{array}{l}\text { To reflect on values, including } \\
\text { egocentric and ethnocentric values that } \\
\text { may have been learned through early } \\
\text { childhood }\end{array}$ & Pre-trip \\
\hline & & $\begin{array}{l}\text { To be able to identify similarities and } \\
\text { differences that may exist between and } \\
\text { within cultures }\end{array}$ & $\begin{array}{l}\text { While abroad } \\
\text { Post-trip }\end{array}$ \\
\hline & & $\begin{array}{l}\text { To understand the impact of culture- } \\
\text { specific values on the formation of } \\
\text { their understanding of self and others }\end{array}$ & Post-trip \\
\hline $\begin{array}{l}\text { Historical } \\
\text { Knowledge }\end{array}$ & $\begin{array}{l}\text { Readings, lectures, } \\
\text { films, site visits, } \\
\text { art \& culture }\end{array}$ & $\begin{array}{l}\text { To discover cultural practices and } \\
\text { worldviews (history, language, the } \\
\text { arts, sociopolitical factors, family } \\
\text { structures, religious practices, etc.) }\end{array}$ & $\begin{array}{l}\text { Pre-trip } \\
\text { While abroad }\end{array}$ \\
\hline \multirow{2}{*}{$\begin{array}{l}\text { Experience/ } \\
\text { Cognitive } \\
\text { Dissonance } \\
\text { (Knowledge) }\end{array}$} & \multirow{2}{*}{$\begin{array}{l}\text { Cross-cultural } \\
\text { dialogues, } \\
\text { collaboration, } \\
\text { immersion }\end{array}$} & $\begin{array}{l}\text { To engage and interact with another } \\
\text { culture that is different than your own }\end{array}$ & \multirow[t]{2}{*}{$\begin{array}{l}\text { Pre-trip } \\
\text { While abroad }\end{array}$} \\
\hline & & $\begin{array}{l}\text { To recognize and experience } \\
\text { differences within and across cultures }\end{array}$ & \\
\hline \multirow[t]{2}{*}{ Ability } & $\begin{array}{l}\text { Written materials, } \\
\text { Self-assessment } \\
\end{array}$ & $\begin{array}{l}\text { To determine the intentions for } \\
\text { studying another culture }\end{array}$ & $\begin{array}{l}\text { Pre-trip } \\
\text { While abroad }\end{array}$ \\
\hline & $\begin{array}{l}\text { Cross-cultural } \\
\text { dialogues, immersion }\end{array}$ & $\begin{array}{l}\text { To understand, recognize and reflect } \\
\text { on cultural differences and worldviews }\end{array}$ & $\begin{array}{l}\text { While abroad } \\
\text { Post-trip }\end{array}$ \\
\hline Attitudes & $\begin{array}{l}\text { Case studies, role } \\
\text { play, critical } \\
\text { incidents, } \\
\text { simulations }\end{array}$ & $\begin{array}{l}\text { To facilitate a shift from original way } \\
\text { of thinking }\end{array}$ & $\begin{array}{l}\text { Pre-trip } \\
\text { While abroad } \\
\text { Post-trip }\end{array}$ \\
\hline Behaviors & $\begin{array}{l}\text { Cross-cultural } \\
\text { dialogues, immersion }\end{array}$ & $\begin{array}{l}\text { To facilitate a change in actions, } \\
\text { reactions, and interactions with people } \\
\text { of different cultures }\end{array}$ & $\begin{array}{l}\text { Pre-trip } \\
\text { While abroad } \\
\text { Post-trip } \\
\end{array}$ \\
\hline $\begin{array}{l}\text { Awareness/ } \\
\text { Experience } \\
\text { (knowledge) }\end{array}$ & $\begin{array}{l}\text { Immersion, cross- } \\
\text { cultural dialogues, } \\
\text { collaboration }\end{array}$ & $\begin{array}{l}\text { To provide students with an experience } \\
\text { that would push them outside of their } \\
\text { comfort zone (cognitive dissonance) }\end{array}$ & While abroad \\
\hline Skills/Culture & $\begin{array}{l}\text { Simulation, } \\
\text { Role play, Exercises, } \\
\text { Immersion }\end{array}$ & $\begin{array}{l}\text { To be able to communicate and engage } \\
\text { in dialogue with another culture }\end{array}$ & $\begin{array}{l}\text { Pre-trip } \\
\text { While abroad } \\
\text { Post-trip } \\
\end{array}$ \\
\hline
\end{tabular}

\footnotetext{
Note: adapted from Fowler \& Blohm, 2004
} 
Fourth, collaboration among disciplines should be incorporated in short-term study abroad courses. We cannot continue to teach study abroad classes as traditional oncampus courses and expect students to successfully move through the Development of $\underline{I C C}$, if the course content or design of the course does not change. Pre-course sessions should engage with different teaching methods and collaborate with faculty outside of their respective department. We should not expect faculty to be an expert on culture, attitude and value theory, social learning theory, cross-cultural skills and leadership. Experts from the respective fields (e.g. Counseling, Sociology, Psychology, Learning and Teaching) should be brought in to assist with Development of ICC.

Fifth, cultural awareness activities should be built in throughout the course. Instructors should provide a space for participants to engage in purposeful moments for reflection and connection prior, during, and after the course. Not only is it important for participants to reflect on their own values going into the course, but they also need to have the opportunity to reflect on their attitudes and behaviors while abroad and when they return.

Lastly, since short-term study abroad courses were found to constrain ICC development due to the length of the course, educators should consider creating hybrid courses. Since personal and financial contrainsts hinder graduate students from going abroad for a semester or longer, a hybrid course would meet for an entire semester and incorporate a short-term study abroad experience for 7-10 days. In order to be effective, the hybrid course would need to be designed for the Development of ICC throughout the semester. 


\section{Future Research Recommendations}

The results of this study highlight several areas for further research. First, it would be beneficial to conduct additional studies using different methodologies. For example, conducting an ethnography of one or more students enrolled in a study abroad course to observe and asses the Development of ICC while abroad in another country would give insights to actual behaviors versus self-perceived behaviors. In addition, it would be beneficial to compare and develop a quantitative construct to measure all characteristics and levels for the Development of ICC, which would allow for pre and post assessment.

Second, future research should investigate whether or not the Development of ICC is applicable to other populations (e.g. undergraduate students), other contexts (e.g. workplace), and/or cultural groups (e.g. minority students). For example, does the theoretical model apply to undergradaute students who study abroad for a semester? How do employers facilitate Development of ICC in the workplace? How did being a minority student contribute to developing ICC?

Third, the Development of ICC should be further explored with social learning theories such as Howell's (1982) theory of development on learner's competency or Festinger's (1957) theory of cognitive dissonance. Is there a relationship with students' level of learning and level of ICC? Is there a relationships with students' level of ICC and cognitive dissonance?

Fourth, courses should be created that are specific to developing learning outcomes to target the Development of ICC, and studies should assess whether or not students move through the developmental process at a faster rate with the use of cognitive, active, and intercultural teaching methods. 


\section{Conclusions}

It would make sense that development of ICC was depicted as stages or steps in the pilot study since reflection papers were the only source of data. The findings in this study used archived records to give a context for the case studies, interviews to understand how participants defined ICC as a result of their study abroad course, and document analysis to triangulate the data and identify additional themes to compare and contrast. The data in this study proved to provide more depth and the cross-case analysis allowed the researcher to identify patterns which resulted in a new theoretical framework referred to as the Development of ICC.

Replication of characterisitics identified in participants' definitions of ICC showed that the theorotical model could be reproduced and used to explore where individuals are in the process to developing ICC. In addition, findings indicated that short-term study abroad programs would be well-advised to take the competencies of the participants into account, since prior experiences shape intentions to develop ICC. Moments of cognitive dissonance and having a space for reflection prior, during, and after the course were found to facilitate ICC development. This study also shows that when students had limited interactions with the culture of the host country, their ICC development was constrained.

The results of this study are important for international educators who are developing, planning, and assessing study abroad programs for graduate students. In addition, students interested in developing their ICC will gain a better understanding of the factors that facilitate and challenge their efforts. 


\section{References}

Anderson, P., Lawton, L., Rexeisen, R., \& Hubbard, A. (2006). Short-term study abroad and intercultural sensitivity: A pilot study. International Journal of Intercultural Relations, 30, 457-469.

Ang, S., \& Van Dyne, L. (2008). Handbook of cultural intelligence: Theory, measurement, and applications. Armonk, New York: M.E. Sharpe.

Ang, S., Van Dyne, L., Koh, C., Ng, K.Y., Templer, K.J., Tay, C., et al. (2007). Cultural intelligence: Its measurement and effects on cultural judgment and decision making, cultural adaptation and task performance. Management and Organization Review, 3(3), 335-371.

Bennett, M.J., Bennett, J.M., \& Landis, D. (Eds.). (2004). Handbook of intercultural training $\left(3^{\text {rd }}\right.$ ed.). Thousand Oaks, CA: Sage Publications.

Bhawuk, D.P.S., \& Brislin, R. (1992). The measurement of intercultural sensitivity using the concepts of individualism and collectivism. International Journal of Intercultural Relations, 16(4), 413-436.

Boyatzis, R.E. (1982). The competent manager. New York, NY: John Wiley and Sons.

Brown, G.W. (2008). Globalization is what we make of it: Contemporary globalization theory and the future construction of global interconnection. Political Science Review, 6, 42-53.

Buczynski, S., Lattimer, H., Inoue, N., \& Alexandrowicz, V. (2010). Developing a policy for an international experience requirement in a graduate teacher education program: a cautionary tale, Teaching Education, 21(1), 33-46.

Canfield, B., Low, L., \& Hovestadt, A. (2009). Cultural immersion as a learning method for expanding intercultural competencies. The Family Journal, 17(4), 318-322.

Castellanos, J., Gloria, A.M., Mayorga, M., \& Salas, C. (2007). Student affairs professionals' self-report on multicultural competence: Understanding awareness, knowledge, and skills. NASPA Journal, 44(4), 643-663.

Cheng, D.X., \& Zhao, C. (2006). Cultivating multicultural competence through active participation: Extracurricular activities and multicultural learning. NASPA Journal, 43(4), 13-38.

Chieffo, L., \& Griffiths, L. (2004). Large-scale assessment of student attitudes after a short-term study abroad program. Frontiers: The Interdisciplinary Journal of Study Abroad, 10, 165-177. 
Chin, C., Gu, J., \& Tubbs, S. (2001). Developing global leadership competencies. Journal of Leadership Studies, 7(3), 20-31.

Corbitt, J. N. (1998). Global awareness profile. Yarmouth, ME: Intercultural Press.

Creswell, J.W. (1998). Qualitative inquiry and research design: Choosing among five traditions. Thousand Oaks, CA: Sage Publications.

Cushner, K., \& Brislin, R.W. (1996). Interactions: A practical guide (2nd ed.). Thousand Oaks, CA: Sage Publications.

D'Andrea, M., Daniels, J., \& Heck, R. (1991). Evaluating the impact of multicultural counseling training. Journal for Counseling and Development, 70(1), 143-150.

Dansby, M.R., \& Landis, D. (1991). Measuring equal opportunity in the military environment. International Journal of Intercultural Relations, 15(4), 399-406.

Deardorf, D.K. (2004). The identification and assessment of intercultural competence as a student outcome of international education at institutions of higher education in the United States (Doctoral dissertation, North Carolina State University, 2004). (UMI No. AAT 3128751).

Deardorf, D.K. (2005). A matter of logic? Using a programs logic model, institutions of higher education can determine outcomes of internationalization efforts in a meaningful way. International Educator, 14(3), 26-31.

Deardorf, D.K. (2006). The identification and assessment of intercultural competence as a student outcome of internationalization [Electronic version]. Journal of Studies in International Education, 10, 241.

Der-Karabetian, A., \& Metzer, J. (1992). The cross-cultural world-mindedness scale and political party affiliation. Psychological Reports, 72, 1069-1070.

Donnelly-Smith, L. (2009). Global learning through short-term study abroad. Peer Review: emerging trends and key debates in undergraduate education, 11(4), 12 15.

Donmoyer, R. (1990). Generalizability and the single-case study. In E. W. Eisner \& A. Peshkin (Eds.), Qualitative inquiry in education: The continuing debate. New York: Teachers College Press.

Dwyer, M. (2004). More is better: The impact of study abroad program duration. Frontiers: The Interdisciplinary Journal of Study Abroad, 10, 151-164.

Early, P.C., Ang, S., \& Tan, J.S. (2006). CQ: Developing cultural intelligence at work. Stanford, CA: Stanford University Press. 
Edmonds, M.L. (2010). The lived experiences of nursing students who study abroad : A qualitative inquiry. Journal of Studies in International Education, 14, 545.

Engle, L., \& Engle, J. (2003). Study abroad levels: Toward a classification of program types. Frontiers: The Interdisciplinary Journal of Study Abroad, 9, 1-20.

Engle, L., \& Engle, J. (2004). Assessing language acquisition and intercultural sensitivity development in relation to study abroad program design. Frontiers: The Interdisciplinary Journal of Study Abroad, X, 219-236.

Festinger, L. (1957). A theory of cognitive dissonance. Evanston, Ill.; Row Peterson.

Flack, M.J. (1976). Results and effects of study abroad. The Annals of the American Academy of Political and Social Science, 424, 107-117.

Forum on Education Abroad. (2007, May). The standards of good practice for education abroad. Retrieved February 19, 2011, from http://www.forumea.org/documents/ForumStandards.pdf

Fowler, S.M., \& Blohm, J.M. (2004). An analysis of methods for intercultural training. In D. Landis, J.M. Bennett, \& M.J. Bennett (Eds.). Handbook of intercultural training (pp. 85-128). Thousand Oaks, CA: Sage Publications.

Gary Cook Graduate School of Leadership (2011a). A Tradition of Leadership. Retrieved from Dallas Baptist University website: http://www3.dbu.edu/dbu report/documents/Fall201011.pdf

Gary Cook Graduate School of Leadership (2011b). Leadership Studies. Retrieved from Dallas Baptist University website:

http://www3.dbu.edu/leadership/phdLeadership.asp

Glesne, C. (1999). Becoming qualitative researchers. New York: Longmann.

Gordon, P., Heischmidt, K., Sterrett, J., \& McMillan, H. (2009). Internationalising the business program: One college's approach. Paper presented at the Marketing Management Association Fall Educator's Conference.

Guba, E.G. (1981). Criteria for assessing the trustworthiness of naturalistic inquiries. Educational Resources Information Center Annual Review Paper, 29, 75-91.

Hammer, M. R., \& Bennett, M. J. (1998). The intercultural development inventory (IDI) manual. Portland, OR: Intercultural Communication Institute.

Harris, P. R., Moran, R. T., \& Moran, S. V. (2007). Managing cultural differences: 
Global leadership strategies for the 21 st century $\left(6^{\text {th }}\right.$ ed.). Burlington, VT: Elsevier Butterworth-Heinemann.

Hett, E.J. (1993). The development of an instrument to measure global-mindedness. (Doctoral dissertation, University of San Diego, 1993). (UMI: 9408210).

Hofstede, G. (2001). Cultures's consequences: Comparing values, behaviors, institutions, and organizations across nations $\left(2^{\text {nd }}\right.$ ed.). Thousand Oaks, CA: Sage Publications.

Hofstede, G., \& Hofstede, G.J. (2004). Cultures and organizations: Software of the mind ( $2^{\text {nd }}$ ed.) New York: McGraw-Hill.

House, R.J. \& Javidan, M. (2004). Overview of GLOBE. In R.J. House \& Global Leadership and Organizational Behavior Effectiveness Research Program (eds.), Culture, leadership, and organizations: The GLOBE study of 62 societies (pp. 948). Thousand Oaks, CA: Sage Publications.

Howell, W.S. (1982). The empathic communicator. Bellmont, CA: Wadsworth.

Institute of International Education. (2008). Open doors 2008: U.S. students studying abroad. Washington, DC: Institute of International Education.

Institute of International Education. (2010). Open doors 2010: Fast facts. Washington, DC: Institute of International Education.

Institute of International Education. (2011). Institutions by undergraduate participation in study abroad, 2009/10. Open Doors Report on International Educational Exchange. Retrieved from http://www.iie.org/opendoors

Jun, H. (2010). Social justice, multicultural counseling, and practice: Beyond a conventional approach. Thousand Oaks, CA: Sage Publications.

Karim, A.U. (2003). A developmental progression model for intercultural consciousness: A leadership imperative. Journal of Education for Business, 79(1), 34-39.

Kehl, K., \& Morris, J. (2007). Differences in global-mindedness between short-term and semester -long study abroad participants at selected private universities. Frontiers: The Interdisciplinary Journal of Study Abroad, 15, 67-79.

Kelly, C., \& Meyers, J. (1995). The cross-cultural adaptability Inventory: Selfassessment. Minneapolis, MN: NCS Pearson.

King, P.M., \& Howard-Hamilton, M. (2003). An assessment of multicultural competence. NASPA Journal, 40(2), 119-133. 
Kolb, D. A. (1999). The Kolb learning style inventory: Version 3. Boston: HayGroup.

Lindsey, E.W. (2005). Study abroad and values development in social work students. Journal of Social Work Education. 41(2), 229-249.

Lokkesmoe, K. J. (2009). A grounded theory study of effective global leadership development strategies: Perspectives from Brazil, India, and Nigeria. (Doctoral dissertation, University of Minnesota, 2009). (UMI: 13010247)

Long, S., Akande, Y., Purdy, R., \& Nakano, K. (2010). Deepening learning and inspiring rigor: Bridging academic and experiential learning using a host country approach to a study tour. Journal of Studies in International Education, 14(1), 89-111.

Malmgren, J., \& Galvin, J. (2008). Effects of study abroad participation on student graduation rates: A study of three incoming freshman cohorts at the University of Minnesota, Twin Cities. NACADA Journal, 28(1), 29-42.

Martinez, C. (2011). 2010-11 Global Center Annual Report. San Diego, California: University of San Diego, School of Leadership and Education Sciences Global Center.

McCrea, R. (2010). Values. In R. Jackson \& M. Hogg (Eds.), Encyclopedia of identity (pp. 854-57).Thousand Oaks, CA: Sage Publications.

Medina-Lopez-Portillo, A. (2004). Intercultural learning assessment: The link between program duration and the development of intercultural sensitivity. Frontiers: The Interdisciplinary Journal of Study Abroad, 10, 179-199.

Mercedes, M., \& Vaughn, B. (2007). Strategic diversity and inclusion management. San Francisco, CA: Diversity Training University International (DTUI) Publications Division, 31-36. Retrieved from presentation on February 13, 2009, University of San Diego.

Merriam, S.B. (1988). Case study research in education. San Francisco, CA: Jossey-Bass Publishers.

Merriam, S.B. (2009). Qualitative research: a guide to design and implementation. San Francisco, CA: Jossey-Bass Publishers.

Mills, L.H., Deviney, D., \& Ball, B. (2010). Short-term study abroad programs: A diversity of options. The Journal of Human Resources and Adult Learning, 6(2), $1-13$.

Miles, M.B., \& Huberman, A.M. (1994) Qualitative data analysis (2nd ed.). Thousand Oaks: Sage Publications. 
Morrison, A. J. (2000). Developing a global leadership model [Electronic version]. Human Resource Management, 39 (2-3), 117-131.

Nash, E. (2011). COUN 515 Multicultural Syllabus [PDF document]. Retrieved from instructor.

Olson, C., \& Kroger, K.R. (2001). Global competency and intercultural sensitivity [Electronic version]. Journal of Studies in International Education, 5(2), 116.

Paige, R.M. (2004). Instrumentation in intercultural training. In D. Landis, J.M. Bennett, \& M.J. Bennett (Eds.). Handbook of intercultural training (pp. 85-128). Thousand Oaks, CA: Sage Publications.

Paige, R. M., Cohen, A. D., \& Shively, R. L. (2004). Assessing the impact of a strategiesbased curriculum on language and culture learning abroad. Frontiers: The Interdisciplinary Journal of Study Abroad, 10, 253-276.

Paige, R.M., Fry, G.W., Stallman, E., Josic, J., \& J.E-Jon. (2009). Study abroad for global engagement: Results that inform research and policy agendas. In $\mathrm{L}$. Donelly-Smith (Ed.), Global learning through short-term study abroad. Washington, D.C.: Association of American Colleges and Universities.

Patton, M.Q. (1980). Qualitative evaluation methods. Newbury Park, CA: Sage Publications.

Patton, M.Q. (2002). Qualitative evaluation and research methods. Newbury Park, CA: Sage Publications.

Raby, R.L. (2007). Internationalizing the curriculum: On-and off-Campus strategies. New Directions for Community Colleges, 138, 57- 66.

Reddin, W.J. (1994). Using tests to improve training: The complete guide to selecting, developing and using training instruments. Englewood Cliffs, NJ: Prentice Hall.

Riege, A. (2003). Validity and reliability tests in case study research: A literature review with "hands-on" applications for each research phase. Qualitative Market Research: An International Journal, 6(2), 75-86.

Roizner, M. (1996). A practical guide for the assessment of cultural competence in children's mental health organizations. Boston: Judge Baker Children's Center.

School of Leadership and Education Sciences (2011a). Current Student Profiles. Retrieved from the University of San Diego website: http://www.sandiego.edu/soles/programs/leadership_studies/current_student_profi les/doc_student_profiles.php 
School of Leadership and Education Sciences (2011b). Global Center. Retrieved from the University of San Diego website:

http://www.sandiego.edu/soles/programs/leadership studies/international require ment.php

School of Leadership and Education Sciences (2011c). International Requirement.

Retrieved from the University of San Diego website:

http://www.sandiego.edu/soles/programs/leadership studies/international require ment.php

School of Leadership and Education Sciences (2011d). Strategic Plan. Retrieved from the University of San Diego website:

http://www.sandiego.edu/soles/about/strategic plan.php

Scoffham, S. \& Barnes, J. (2009). Transformational experiences and deep learning: The impact of an intercultural study visit to India on UK initial teacher education students. Journal of Education for Teaching, 35(3), 257-270.

Sheridan, E. (2005). Intercultural competencies for US business leaders in the new millennium (Doctoral dissertation, University of Phoenix, 2005). (UMI: 3172360)

Stearns, P. (2009). Educating global citizens in colleges and universities. New York, NY: Routledge.

Steglitz, I., Gardner, P., \& Gross, L. (2009). Translating study abroad experiences for workplace competencies. Peer Review: emerging trends and key debates in undergraduate education, 11(4), 19-22.

Treverton, G. F., \& Bikson, T. K. (2003). New challenges for international leadership: Positioning the United States for the 21st century. Santa Monica, CA: RAND.

Triandis, H.C. (2004). Forward. In D. Landis, J.M. Bennett, \& M.J. Bennett (Eds.), Handbook of intercultural training (pp. 85-128). Thousand Oaks, CA: Sage Publications.

Tubbs, S.L., \& Schulz, E. (2006). Exploring a taxonomy of global leadership competencies and meta-competencies. Journal of American Academy of Business, 8(2), 29-34.

Tucker, M.F. (1999). Self-awareness and development using the overseas assignment inventory. In S. M. Fowler \& M.G. Mumford (Eds.), Intercultural sourcebook: Cross-cultural training methods (pp. 45-52). Yarmouth, ME: Intercultural Press.

Tye, K.A. (Ed). (1991). Global education: From thought to action (ASCD Yearbook). Alexandira, VA: Association for Supervision and Curriculum. In Moodian, M.A. (2009). Contemporary leadership and intercultural competence: Exploring the 
cross-cultural dynamics within organizations. Thousand Oaks, CA: Sage Publications.

Vande Berg, M. (2001). The assessment of learning outcomes in study abroad. International Educator, 10(2), 31.

Ward, C., \& Kennedy, A. (1999). The measurement of sociocultural adaptation. International Journal of Intercultural Relations, 23(6), 659-677.

Wibbeke, E.S. (2009). Global business leadership. Burlington, MA: ButterworkHeinenmann.

Williams, T.R. (2005). Exploring the impact of study abroad on students' intercultural communication skills: Adaptability and sensitivity. Journal of Studies in International Education, 9, 356.

Yin, R.K. (2003). Case study research: Design and methods ( $3^{\text {rd }}$ ed.). Thousand Oaks, CA: Sage Publications.

Yin, R.K. (1994). Case study research: Design and methods (2 $2^{\text {rd }}$ ed.). Thousand Oaks, CA: Sage Publications.

Yin, R.K. (2008). Case study research: Design and methods ( $4^{\text {th }}$ ed.). Thousand Oaks, CA: Sage Publications.

Younes, M. \& Asay, S. (2003). The world as a classroom: The impact of international study experiences on college students. College Teaching, 51(4), 141-147.

Zábojník, J. (2004). A model of rational bias in self-assessments. Economic Theory, 23(2), 259-282. 


\section{Appendix A \\ Recruitment Email}

Dear USD SOLES Global Study Participant/ Dear DBU Oxford, England Summer Institute Participant,

You are invited to take part in a research study to determine how graduate students who participated in a short-term study abroad course define and develop intercultural competence (ICC) and what factors facilitated or constrained ICC development.

You were selected as a possible participant due to your enrollment in a USD SOLES Global Study Course/DBU Oxford, England Summer Institute between September 2008 and August 2011/August 2006 and August 2011 (for DBU). The purpose of the qualitative comparative case study is to delve deeper into actual student learning outcomes by reviewing archival records, personal documents and interviewing graduate students who participated in a short-term study abroad course. The results of the study will provide important planning and assessment implications for international educators who are using study abroad programs to develop intercultural competencies among graduate students.

Your participation is voluntary and your responses will remain confidential. You may withdraw from the interview at any time. You may skip questions and refuse to participate in or discontinue the interview without penalty.

If you are interested in participating in the study, please sign and fax the attached consent to participate in the study. You will be contacted to arrange a 60-90 minute interview. In addition, once the interview process is complete, participants will be contacted and offered a chance to review via email attachment the transcribed data for the purposes of "member checking." Participants will have one week to review the data and check for any inconsistencies or discrepancies.

Warm regards,

Cynthia A. Martinez, M.Ed.

Doctoral Student

Department of Leadership Studies

University of San Diego 


\section{Appendix B - Informed Consent \\ PREPARING GLOBAL LEADERS: \\ A THEORETICAL MODEL FOR UNDERSTANDING THE DEVELOPMENT OF INTERCULTURAL COMPETENCY}

Cynthia Martinez is a doctoral student in Leadership Studies at the University of San Diego. You are invited to participate in a research project she is conducting to determine how graduate students who participated in a short-term study abroad course define and develop intercultural competence (ICC) and what factors facilitated or constrained ICC development.

The project will involve a review of archived records (i.e. official and unofficial documents generated for the program), personal documents (i.e. reflection papers) one interview and one follow-up interview, if needed, which asks questions about your shortterm global study experience. The interview will last 60 to 90 minutes and will include some demographic questions about you, such as your gender, ethnicity, number of times studied abroad and amount of time living in the United States. The interview will take place at a time and location convenient for you. Participation is entirely voluntary and you can refuse to answer any question and/or quit at any time. Should you choose to quit, no one will be upset with you and your information will be destroyed right away. If you decide to quit, there will be no consequences to you.

You may elect to participate in a brief, follow-up interview if there are any remaining questions following your interview, or if the researchers would like clarification of information you provided. Participation in this follow-up interview, just as in the initial interview, is voluntary.

The information you give will be analyzed and studied in a manner that protects your identity. That means that a code number or pseudonym will be used and that your real name will not appear on any of the study materials. All information you provide will remain confidential and locked in a file cabinet in the researcher's office or kept on a password protected computer for a minimum of five years before being destroyed.

The benefit to participating will be in knowing that you helped higher education researchers learn how to better develop intercultural competencies through short-term study abroad programs for graduate students. 
If you have any questions about this research, please contact Cynthia Martinez at (909) 225-9831 or via email at cynthiam-11@sandiego.edu or the faculty member who is overseeing this study, Dr. Lea Hubbard at 619-260-7818 or lhubbard@sandiego.edu, at the University of San Diego.

I have read and understand this form, and consent to the research it describes to me. I have received a copy of this consent form for my records. I will fax a copy of this form to Cindy Martinez at (909) 396-6121 prior to the start of my interview.

Signature of Participant

Date

Name of Participant (Printed)

Signature of Principal Investigator

Date 


\section{Appendix C - Demographic and Narrative Questions}

\section{Demographic Questions}

1. Name (Pseudonym will be give)

2. Age

3. Gender

3. Self-Reported Ethnicity

4. Have you previously studied or traveled abroad? (yes/no).

4a. If yes, please list locations:

4 b. If not, why?

5. How many study abroad courses have you participated in since you started the degree program?

5a. Term(s) you participated in a study abroad course(s)?

5 b. Location of study abroad course(s) (e.g. Mondragón, Spain):

6. Have you lived in the United States for 10 years or more? (yes/no)

6a. If not, where have you lived before?

\section{Narrative Questions for Semi-Structured Interview}

Why did you choose to study to [insert name of country] and enroll in [insert name of course]?

What was the international focus of the course?

How would you define intercultural competence (ICC)?

Has your definition of ICC changed as a result of your participation in a short-term study abroad course? Why or why not?

How would you describe your level of ICC prior to studying abroad? Why?

How would you describe your level of ICC after studying abroad? Why? How do/did you determine there was a change?

Tell me about the course, including pre and post sessions, if any. What was the course like? What teaching methods did the instructor use? What teaching methods were most effective towards enhancing your learning experience? What teaching methods in the course focused on your development of ICC?

Tell me about your time spent abroad [if it isn't discussed in the question above].

How do you think the study abroad course developed your ICC?

What factors facilitated or constrained ICC development? [Participant will be asked to elaborate and expand on factors discussed] 
The following questions are examples that will be used to target the 7 characteristics of ICC:

\section{Values}

What are some of the specific values and beliefs that have shaped who you are?

Are there any values that you were born into that you think have been influenced by your own culture? Please explain.

Where any of your personal values different than the culture you explored abroad? Please explain.

What values did you learn about the country/culture you visited?

\section{Ability}

For USD: What made you decide to study abroad to complete your international experience, since studying abroad was not the only way to fulfill the requirement?

For DBU: Prior to applying/admitted, did you know that you were required to participate in the summer institute as part of your degree program? If yes, was that a draw to the program? Do you think you would have studied abroad if it wasn't required? Would you have preferred a different location? If no, how did you feel when you found out you were required to study abroad?

Did you feel you were prepared to interact with people from a different culture? If yes, please explain. If not, why not?

How did you prepare yourself to study abroad?

Knowledge

What did you know about the culture you were visiting prior to studying abroad?

How did you learn about the culture prior to studying abroad?

How did the course prepare you to learn about another culture?

Did any of your perceptions of the culture change or confirmed while abroad? Please explain.

\section{Awareness}

Did the study abroad course help facilitate your own awareness of your own culture? How or why not? Please explain.

How does your own culture fit in with the culture you studied? 
Do you think your level of awareness has changed as a result of studying abroad? Why or why not?

Can you give me an example of how your awareness has or has not changed?

\section{Attitude}

What were some of the thoughts, feelings and actions you had while abroad?

Did you notice a change in your attitude while abroad? Why or why not? Please explain.

What were some similarities and differences you noticed between your culture and the culture you studied?

Has there been a change in your attitude towards cultural difference since you have been back? Please explain.

How would you describe the attitudes of other participants?

\section{Behavior}

Did you engage with international students or people from the country or culture you visiting? Tell me about your experience.

During your trip to [wherever the study abroad course was], what were the toughest parts for you in terms of adjusting to the new culture? How did you handle it? What did you do?

Can you think of a time when you had to update and/or modify your behavior with someone from a different culture since you returned from studying abroad? Tell me about it. Where was the person from? What was the issue? What did you do? What happened? Can you think of another example when you were not able to modify your behavior? If so, when was it? Why do you think you were not able to modify your behavior?

How would you describe the behaviors of other participants?

$\underline{\text { Skills }}$

What skills, if any, do you think are needed to develop ICC?

Were there any skills you learned prior to the course to help develop your ICC? If so, please explain.

Were there any skills you learned during or as a result of the course to help develop your ICC? If so, please explain.

Can you give me an example how the skills mentioned above helped you to communicate and interact with another culture while you were abroad? 
OR

Can you tell me what skills you think would have been helpful to have to communicate and interact with another culture while you were abroad?

Figure 1 (below) was developed as a result of a pilot study and will be shared (sent via email for those over the phone) with participants in this study after the structured interview to test and trace their development of ICC:

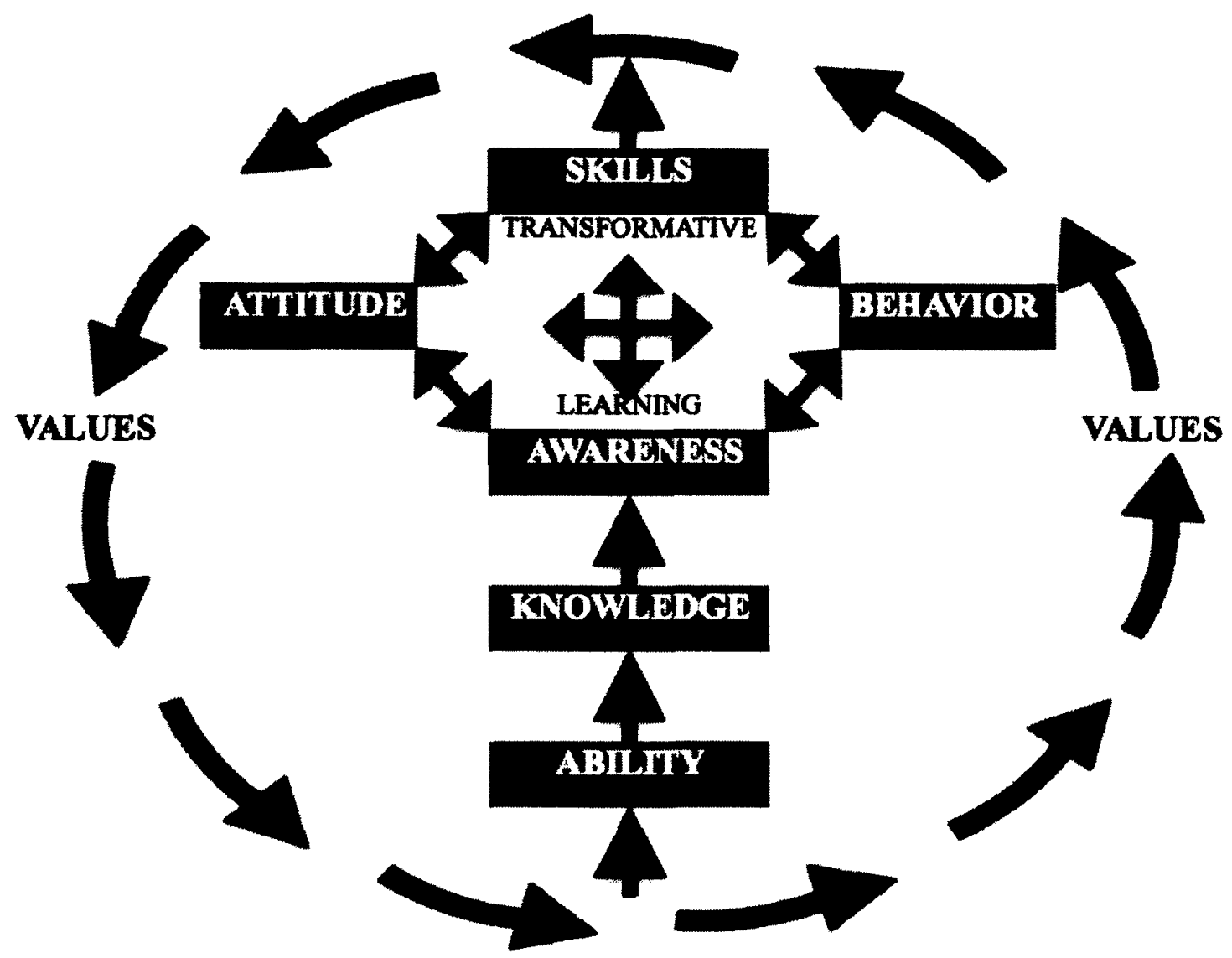

I would like to share a working model that was developed in a pilot study and use it to trace your development of ICC. Give brief description of each characteristic.

1. What are your initial thoughts about the model when you look at it?

2. Can you walk me through this model based on your development of ICC?

3. Does it apply?

4. Is there anything you would add, move, or delete?

5. Is there anything that you would put in a different order or arrangement?

6. Is there anything else you would like to say about the model? 


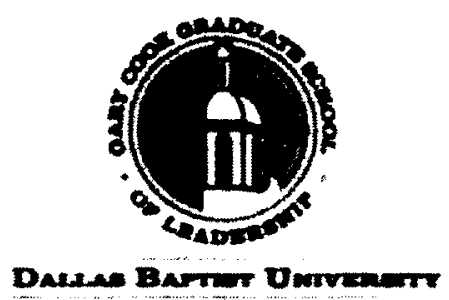

Ixwernber 46. 2011

Cinthia Martimer.

Re: (PHS: $: 2011+12-161$

Title of Study: Preparing Gilohal Lewders: Developing Intercuhtural Compoterwien Through Shum-term Situly Abouad Proyrams

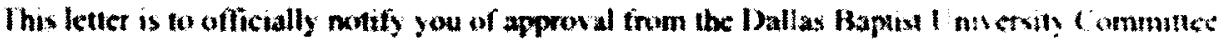
for Prolection of lluman Participants fin you to condext rescarch at Dallss Haytu: I nusets

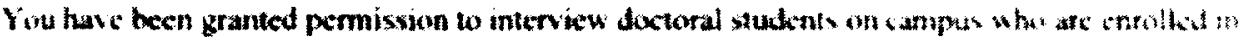
a decoral keadership studies program and participaled in a short-lem study atrowa courix between Seprember 2008 and August 2011

This permission is granted with the understanding that you will provide evidence of IRB approval from the Iniversity of San Diego before interviews are conducted and will provide adequate safeguards for the rights and welfare of the purticipants in this stud?

You are authorized to implement this stody as prescnted as of the Date of f-ndeternat

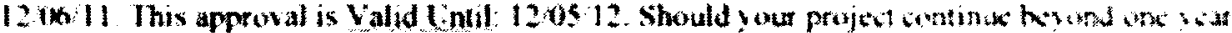

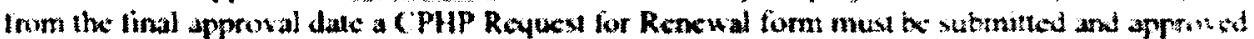

If you have any guestions, please contact me

Simitrely.

Dr. Suc Kavli

Committe for Protection of Human Participants. Chair

Dallas Haplist University

$\$$ \$oo Mountwin Creck Parkway

Dallas. TX 75211

214333.5381

such adbuxdu 